\title{
RESPONSIVE MATERIALS VIA DIELS-ALDER CHEMISTRY
}

\author{
A Thesis \\ Presented to \\ The Faculty of California Polytechnic State University, \\ San Luis Obispo
}

\begin{abstract}
In Partial Fulfillment
of the Requirements for the Degree

Master of Science in Polymers and Coatings (Chemistry Department)
\end{abstract}

by

Gregory Alan Strange

December 2011 
(C) 2011

Gregory Alan Strange

ALL RIGHTS RESERVED 
COMMITTEE MEMBERSHIP

TITLE: RESPONSIVE MATERIALS VIA DIELS-ALDER CHEMISTRY

AUTHOR: Gregory Alan Strange

DATE SUBMITTED: December 2011

COMMITTEE CHAIR: Dr. Philip J. Costanzo, Assistant Professor

COMMITTEE MEMBER: Dr. Raymond H. Fernando, Professor

COMMITTEE MOMBER: Dr. Chad Immoos, Associate Professor 


\section{ABSTRACT \\ RESPONSIVE MATERIALS VIA DIELS-ALDER CHEMISTRY \\ Gregory Alan Strange}

The corrosion of infrastructure imposes a significant monetary cost, and at times human cost, upon society. Methods to improve corrosion resistance of materials are described herein which utilize the reversibility of the Diels-Alder reaction to impart thermal responsiveness upon materials. Such stimuli responsiveness can potentially play a role in self healing properties which lead to reduced cracking and thus increased corrosion protection.

Reversible Diels-Alder chemistry was utilized to manipulate the surface energy of glass substrates. Hydrophobic dieneophiles were prepared and attached to glass slides and capillaries to yield a nonwetting surface. Thermal treatment of the surfaces cleaved the Diels-Alder linkage, and resulted in the fabrication of a hydrophilic surface. Preliminary analysis utilized contact angle (CA) measurements to monitor the change in surface energy, and observed a hydrophilic state $\left(\mathrm{CA}-70 \pm 3^{\circ}\right)$ before attachment of the dieneophile to a hydrophobic state $\left(\mathrm{CA}-101 \pm 9^{\circ}\right)$ followed by regeneration of the hydrophilic state $\left(\mathrm{CA}-70 \pm 6^{\circ}\right)$ upon cleavage of the Diels-Alder linkage. The treatments were then applied to glass capillaries, with effective treatment confirmed by fluid column measurements. Patterned treatments were also demonstrated to provide effective fluid flow gating. 
Reversible Diels-Alder linkages were incorporated into polymer thermoset binding resins in order to provide a means by which a crosslinked thermoset could undergo stimuli responsive reversible crosslinking. The binder systems which were utilized included two types of amine curing agents, polydimethylsiloxane (PDMS) and Jeffamine ${ }^{\circledR}$ polyetheramines (PEA), and two types of epoxy resins, EPON resin based on diglycidyl ether of Bisphenol-A and epoxidized soybean oil. Various dienes and dienophiles were employed to functionalize the selected binder systems and were met with various degrees of success. The synthetic technique which proved to be the most promising was the Diels-Alder modification of the epoxidized soybean oil. 


\section{ACKNOWLEDGEMENTS}

First and foremost I would like to thank Dr. Phil Costanzo, who with every failure was able to find ten-fold the opportunity. In the laboratory and in life, Dr. Costanzo has served as a mentor, bringing me forward both as a scientist and a person. I am lucky that I can count him not only as an advisor, but as a friend. I would also like to thank the Cal Poly Polymers and Coatings program and the Chemistry and Biochemistry Department faculty for their guidance, support, and advice throughout the duration of my time at Cal Poly.

I would like to give a special thanks to Dr. Greg Baxley, my first general chemistry professor, without whom I would not have come to know the beauty of chemistry, thank you.

I would like to thank Philip Dirlam, Dr. Joshua Orlicki, and Dr. Eric Wetzel at the Army Research Laboratory for their assistance in development of reversible surface treatments.

I would like to thank Dr. Dan Savin and Dr. Adam Richardson for the opportunity and guidance they gave me as an REU student at the Universtiy of Southern Mississippi. 
TABLE OF CONTENTS

\section{Page}

LIST OF TABLES

xi

LIST OF FIGURES Xii

LIST OF SCHEMES xvi

1. POLYMERIC COMPOSITE MATERIALS 1

1.1. INTRODUCTION

1.2. THERMOPLASTICS AND THERMOSETS 2

1.3. THERMOSET MATRIX MATERIALS 5

1.4.COMPOSITE MATERIALS 10

1.5.DISPERSION OF NANOFILLERS 12

1.6. SELF HEALING MATERIALS

$\begin{array}{ll}\text { 1.7. REFERENCES } & 18\end{array}$

2. CONTROLLING SURFACE ENERGY AND WETABILITY WITH DIELS-

$\begin{array}{ll}\text { ALDER CHEMISTRY } & 20\end{array}$

2.1. INTRODUCTION 20

3. RESPONSIVE MATRIX AND NANOFILLERS VIA DIELS-ALDER 21 CHEMISTRY

$\begin{array}{ll}\text { 3.1. INTRODUCTION } & 21\end{array}$

3.2. EXPERIMENTAL APPROACH 25 
3.2.1. DIELS-ALDER LINKAGE OPTIMIZATION 26

3.2.2. AMINE CURING AGENT MODIFICATION 28

3.2.2.1. POLYDIMETHYLSILOXANE MODIFICATION 28

3.2.2.2. JEFFAMINE® POLYETHERAMINE MODIFICATION 29

3.2.3. EPOXY RESIN MODIFICATION 32

3.2.3.1. EPON EPOXY RESIN MODIFICATION 32

3.2.3.2. SOYBEAN OIL MODIFICATION 33

3.3. RESULTS AND DISCUSSION 38

3.3.1. INCONSISTENCIES WITH CHLOROSILANES 39

3.3.2. CRYSTALLINITY, SOLUABILITY AND MICHAEL 39

ADDITION OF MALEIMIDE COMPOUNDS

3.3.3. SELF EPOXIDE OPENING OF EPOXIDIZED 42

SOYBEAN OIL

3.3.4. CONCLUSIONS AND FUTURE WORK 43

3.4. EXPERIMENTAL TECHNIQUES 46

3.4.1. MATERIALS 46

$\begin{array}{ll}\text { 3.4.2. INSTRUMENTATION } & 46\end{array}$

3.4.3. SYNTHETIC TECHNIQUES 46

3.4.3.1. SYNTHESIS OF CARBOXY-ESTER-FURAN (1) 46

3.4.3.2. SYNTHESIS OF BOC-FURFURYLAMINE (2) 47

3.4.3.3. SYNTHESIS OF CARBOXY MALEIMIDE (3) 47

3.4.3.4. SYNTHESIS OF PHENOLIC MALEIMIDE (4) 48

3.4.3.5. SYNTHESIS OF MALEIMIDE PDMS (5) 49 
3.4.3.6. SYNTHESIS OF BOC-AMINE-DA-PDMS (6) 49

3.4.3.7. SYNTHESIS OF AMINE-DA-PDMS (7) 49

3.4.3.8. SYNTHESIS OF MALEIMIDE JEFFAMINE® 50 T-403 (8)

3.4.3.9. SYNTHESIS OF EPOXIDIZED SOYBEAN OIL (13) 51

3.4.3.10. SYNTHESIS OF DIENE-SOYBEAN OIL (14) 51

3.4.3.11. SYNTHESIS OF PHENOL-DA-SOYBEAN OIL (15) 52

3.4.3.12. SYNTHESIS OF ACETYLATED PHENOL-DA- 52 SOYBEAN OIL (16)

3.5. REFERENCES 54

4. CONCLUSIONS AND FUTURE APPLICATIONS 55

4.1.THE FUTURE OF COMPOSITES AND NANOCOMPOSITES 55

4.2. CONTROL OF SURFACE ENERGY AND WETABILITY VIA 55 DIELS-ALDER CHEMISTRY

4.3. RESPONSIVE MATRIX AND NANOFILLERS VIA DIELS-ALDER 56 CHEMISTRY

5. APPENDIX A - Langmuir 2009, 26, 3942 
Table 3.1. Reversible and permanent crosslink sites per molecule of modified soy-bean oil based on the percentage of compound 4 reacted with a baseline $100 \%$ of diene available for reaction. 
Figure 1.2.1. ${ }^{8}$ Two main groups of polymeric materials.

(a) Thermoplastics and (b) Thermosets which contain covalent crosslinks between chains.

Figure 1.2.2. Interactions between polymer chains: (a) hydrogen bonding; (b) ionic interactions.

Figure 1.3.1. ${ }^{13}$ The crosslinking of epoxy amine systems utilizing primary epoxides with both primary and secondary amines, and hydroxyl groups.

Figure 1.3.2. The synthesis of diglycidal ether of bisphenol $A$ and its formation into a family of epoxy prepolymers. ${ }^{14}$

Figure 1.3.3. a) A trifunctional low molecular weight $(440 \mathrm{~g} / \mathrm{mol})$ polyetheramine (Jeffamine $® \mathrm{~T}-403$ ) used primarily in composite resins ${ }^{16}$ b) A difunctional mid range molecular weight $(2000 \mathrm{~g} / \mathrm{mol})$ polyetheramine (Jeffamine ${ }^{\circledR}$ ED-2003) used primarily in water based epoxy coatings. ${ }^{17}$

Figure 1.3.4. The relative reactivity of amine curing agents as a result of selective steric hinderence. ${ }^{18}$

Figure 1.3.5. Catalysts for the reaction between isocyanates and amines, water and polyols. ${ }^{19}$

Figure 1.3.6. The general synthesis of isocyanate polyurethane prepolymers. ${ }^{21}$

Figure 1.4.1. The general types of fillers found in modern micro and nano scale composites. Filled composites are also known as skeletal composites; flake composites are also known as plate like composites. ${ }^{25}$

Figure 1.5.1. AFM depiction of aggregation and dispersion of silica nanoparticles in a polystyrene thermoplastic with and without a polymer tether

Figure 1.5.2. Schematic of the effect of polymer tether molecular weight on nanoparticle dispersion. 
Figure 1.5.3. The dispersion of $\mathrm{SiO}_{2}$ nanoparticles (70nm diameter)

as a function of the molecular weight of a polystyrene tether grafted from the surface of the nanoparticle via atom transfer radical polymerization (ATRP). Molecular weights of tethers are: $A=5400$, $B=9000, C=16800, D=24600, E=26500 .^{28}$

Figure 1.6.1. a) The polymerization of DCPD using Grubbs' catalyst. b) The healing of a crack with PolyDCPD which was polymerized from DCPD using Grubbs' catalyst released from ruptured microcapsules dispersed throughout the material. c) A schematic of the healing of a crack using healing agent released from microcapsules in a material. ${ }^{34}$

Figure 1.6.2. a) The cardiovascular system on which the biomimetic vascular self healing system is based. b) A self healing material which releases epoxy healing material from an artificial vascular network (scale bar $5 \mathrm{~mm}$ ). ${ }^{34}$

Figure 3.1.1. Transmitted optical microscopy of crack tip damage zone in a polypropylene / $15 \mathrm{wt} . \% \mathrm{CaCO}_{3}$ nanocomposite depicting craze formation. ${ }^{1}$

Figure 3.1.2. Schematic representation of the formation of a craze in both an (a) virgin polymeric matrix, and a (b) polymer nanocomposite matrix. ${ }^{5}$

Figure 3.1.3. Transmission electron micrograph (TEM) of polymer nanocomposite showing stages of (a) precraze, (b) premature, (c) transition, and (d) mature regions. The lining up of nanoparticles can be seen along the precraze and the aggregation of nanoparticles can be seen in the mature craze..$^{5}$ (Scale bar is $200 \mathrm{~nm}$ )

Figure 3.1.4. TEM and corresponding Scheme of the the preferential migration of nanoparticles to the precraze in a polymer nanocomposite. $^{5}$

Figure 3.2.1. Reversible Diels-Alder adduct whose formation is temperature dependent. Red - Diene, Furan. Blue - Dienophile, Maleimide.

Figure 3.2.2. Huntsman Jeffamine ${ }^{\circledR}$ amine terminated polyethers. 
Figure 3.2.3. (a) The general triglyceride form of fatty oils extracted from biological sources. The $\mathrm{R}$ groups exist as a distribution of the fatty acids found in (b). One of the R groups is shown as linoleic acid in this Figure and in the following Schemes as it is the most prevalent fatty acid foud in soy-bean oil . ${ }^{11}$

Figure 3.3.1. The conversion of chlorosilane terminated PDMS to silanol terminated PDMS by water followed by the subsequent reaction of silanol groups with chlorosilanes leading to chain extention.

Figure 3.3.2. The permanent michael addition of silanol to maleimide. $\quad 40$

Figure 3.3.3. The permanent crosslinking of Jeffamine $₫$ systems due $\quad 40$ to the michael addition of amines to the maleimide.

Figure 3.3.4. The self opening of soy-bean oil epoxide molecules 
Scheme 3.2.1. Schematic representation of the utilization of a reversibly crosslinkable thermoset matrix in the enhancement of nanoparticle migration. Particle mobility within DA functionalized matrix. Left to Right : Base material; application of heat; cleave of DA linkages; particle migration; reformation of DA linkages.

Scheme 3.2.2. Synthesis of dienes used in Diels-Alder linkages. (a)

Succinic anhydride modified furfuryl alcohol, (b) Boc protected furfuryl amine.

Scheme 3.2.3. Synthesis of dienophiles used in Diels-Alder linkages.

Scheme 3.2.4. The synthesis of Diels-Aleder modified polydimethylsiloxane.

Scheme 3.2.5. Synthesis for Diels-Alder modification of Jeffamine $®$ $\mathrm{T}-403$. ( $\mathrm{R}$ groups are same as top amine functionalization).

Scheme 3.2.6. Synthesis of Diels-Alder modified EPON epoxy binder. ( $R$ groups are same as right side epoxy functionalization).

Scheme 3.2.7. The modification of soy-bean oil into a thermally responsive epoxy resin containing reversible Diels-Alder linkages.

Scheme 3.2.8. Resulting compound from reaction of compound 14 with compound 4 in THF for $48 \mathrm{~h}$.

Scheme 3.2.9. Resulting compound after acetylation of using acetic anhydride, $\mathrm{Et}_{3} \mathrm{~N}$, in $\mathrm{THF}$ at $60^{\circ} \mathrm{C}$ for $24 \mathrm{~h}$ Followed by the reaction with compound 4 in THF at RT for $48 \mathrm{~h}$

Scheme 3.2.10. Resulting compound from the reaction of compound 14 with compound 1 which has been treated with oxalyl chloride in $\mathrm{CH}_{2} \mathrm{Cl}_{2}$ with catalytic DMF, followed by the reaction with compound 4 in THF at RT for $48 \mathrm{~h}$

Scheme 3.2.11. Synthesis of thermally responsive epoxy resin using compound 15 and epichlorohydrin. 


\section{Polymeric Composite Materials}

\subsection{Introduction}

The use of polymeric materials predates any true scientific understanding of their structure / property relationships. Polymeric materials used as coatings, adhesives, and sealants dates back to $4000 \mathrm{BC}$, with documented use by the Babylonians, Egyptians, and Romans and continued through the middle ages. ${ }^{1}$ Even in the early 1900's with the essentially accidental discovery of nylon, among other polymers, the molecular interactions which gave rise to the unique macroscale properties of polymeric materials remained a mystery. ${ }^{2,3}$ It was not until the latter half of the $20^{\text {th }}$ century that scientists truly began to understand the potential and the range of these materials which had been used for so many centuries and the molecular properties of these materials became a major area of study and research. Such interest in polymers and the abundance of new discoveries about their potential has led to what has been called the "dawn of the polymer age". ${ }^{4}$

One of the uses of polymeric materials throughout history was to act as a coating to protect a substrate which may degrade or corrode under the conditions to which it is submitted. Corrosion in the United States is a severe problem which lies beneath the surface until there is some sort of human cost accompanied with the failure to properly maintain the country's aging infrastructure. For example, the 2007 I-35W bridge collapse in St. Paul, Minnesota over the Mississippi River which failed as a result of corrosion and deferred maintenance, killing 13 people and injuring an additional $145 .^{5}$ 
Following the collapse, a study was done at the University of Michigan which concluded that over 500,000 bridges in the country have been subjected to the same deferred maintenance and could be at risk for collapse. ${ }^{5}$ In addition to the human cost of corrosion, which is only observed periodically, there is a significant underlying monetary cost associated with corrosion maintenance and prevention in the United States of nearly $\$ 300$ billion a year, which corresponds to about $3.1 \%$ of the gross domestic product (GDP) ${ }^{6}$ This cost is not confined to the United States, the world cost of corrosion is approximately 2.2 trillion dollars, again about $3 \%$ of the world GDP. ${ }^{7}$ Studies have shown that using modern coatings in corrosion prevention of infrastructure can save up to $30 \%$ of the current cost of corrosion, and improving the coatings which are currently available could potentially save even more. ${ }^{8}$ For these significant corrosion cost savings, in addition to other potential uses of polymeric materials, further study of polymeric materials is necessary.

\subsection{Thermoplastics and Thermosets}

Polymeric materials can be categorized into two main types, thermoplastics and thermosets. Thermoplastic materials are composed of polymers which remain as individual chains intertwined throughout the bulk material shown in Figure 1.2.1(a) ${ }^{8,9}$ In thermoset materials, polymer chains are covalently bound to one another creating a material which is essentially composed of a single molecule of infinite molecular weight, shown in Figure 1.2.1(b). ${ }^{8,9}$ 


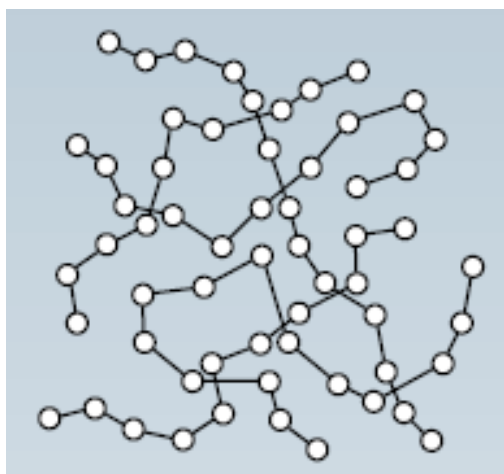

(a) Thermoplastic

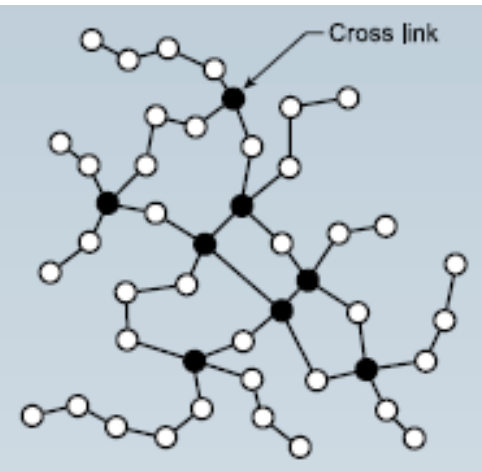

(b) Thermoset

Figure 1.2.1. ${ }^{8}$ Two main groups of polymeric materials. (a) Thermoplastics and (b) Thermosets which contain covalent crosslinks between chains.

Though the polymers in thermoplastic materials are not covalently bound to one another, there are other means by which polymer chains in these materials are able to interact such as hydrogen bonding in nylon or ionic interactions between ionomers, shown in Figure 1.2.2.

(a)<smiles>CCNC(=O)CCCCCCNC(=O)OCC</smiles>

(b)

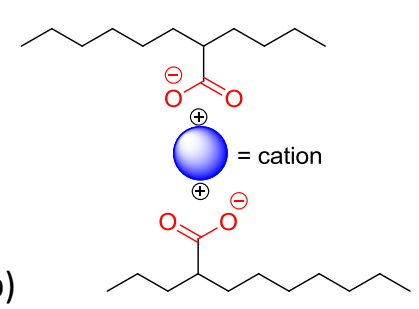

Figure 1.2.2. Interactions between polymer chains: (a) hydrogen bonding; (b) ionic interactions.

Thermoplastic materials are able to be melted and reformed as a result of the polymer chains in the material being free to separate from one another upon melting. Another feature of thermoplastic materials is a sharp glass transition temperature $(\mathrm{Tg})$, the temperature above which a polymeric material displays flexible, rubbery properties, and below which acts rigid and glass like. ${ }^{10} \mathrm{The} \mathrm{Tg}$ of polymeric materials determined by a number of variables which include the 
chemical structure of the monomers of which the polymer is composed and the molecular weight of the polymer chains. The glass transition temperature is a critical property in the potential applications of a polymer and any effects the inclusion of additives has on the Tg must be considered when developing new materials. ${ }^{10}$

Thermoset materials can be tailored to display properties which are not as prevalent in thermoplastic materials of the same polymer structure. This can be accomplished by varying factors such as the density of crosslink points and the amount of branching at each crosslink point. ${ }^{10} \mathrm{~A}$ few of these tailorable properties are an increase in the solvent resistance, thermal properties, and the strength of the material. ${ }^{10}$ The attainment of these properties, however, comes at a cost; thermoset materials lack the ability to be able to be melted and reformed as covalently bound chains are unable to move independently of the bulk material. ${ }^{11}$ The lack of this freedom of mobility not only contributes to the inability to melt, but also to an increased susceptibility to stress fracturing. ${ }^{11,12}$ These stress fractures occur due to the decreasing volume of the material as a result of evaporation of solvent used in processing, natural settling of the material over time, or varying pressure throughout the material, among other factors. ${ }^{11}$ Techniques to increase the fracture toughness of thermoset materials have been reported and employed to varying degrees of effectiveness; however, it is important to consider the effect increasing the toughness of a thermoset has on its strength and thermal properties. ${ }^{12}$ This give and take between material strength and toughness has become a balancing act for material scientists in 
order to develop the polymeric materials which will carry mankind into the next century and beyond.

\subsection{Thermoset Matrix Materials}

Thermoset materials can be made from a multitude of polymer types, two of which will be focused on in this paper, epoxy / amine systems and polyurethane systems. Epoxy / amine based thermoset resin systems are known for their excellent mechanical and electrical properties, adhesion, and chemical resistance, but these resins are notorious for their brittleness, which is a major factor in limiting their end use applications. ${ }^{13}$ An example of the crosslinking in an epoxy amine systems is shown in Figure 1.3.1.

Primary amine-epoxy addition

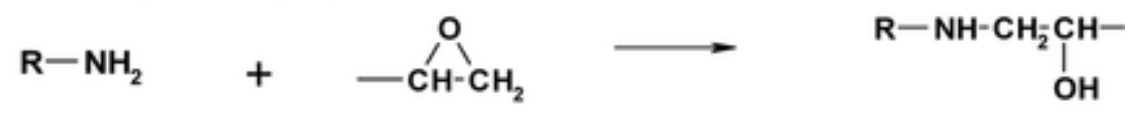

Secondary amine-epoxy addition

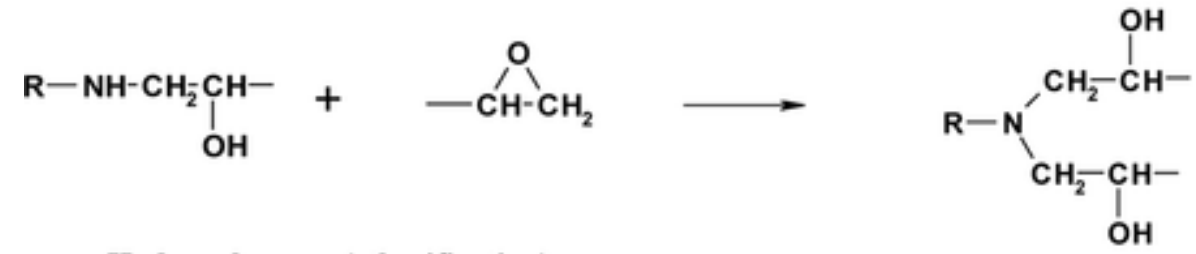

Hydroxyl-epoxy (etherification)

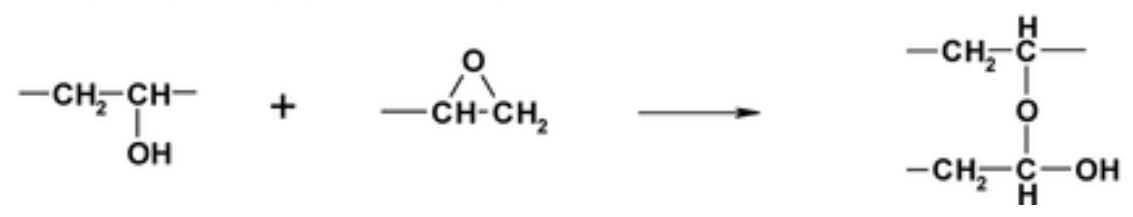

Figure 1.3.1. ${ }^{13}$ The crosslinking of epoxy amine systems utilizing primary epoxides with both primary and secondary amines, and hydroxyl groups.

Epoxy resin systems are a popular option for use in a variety of applications such as adhesives, coatings and structural composites for a number of reasons, including: there is no emission of volatile products as a result of the 
polymerization reaction, flexibility of monomers and co-monomers enabling the ability to target a wide range of $\mathrm{Tg}$ materials, the ability to combine different polymerization chemistries to target specific material properties, and very good adhesion to a variety of surfaces due to polar groups present in the structure. ${ }^{14}$ One of the most commonly used groups of epoxy resins is based on diglycidal ethers of bisphenol A, shown in Figure 1.3.2. ${ }^{14}$

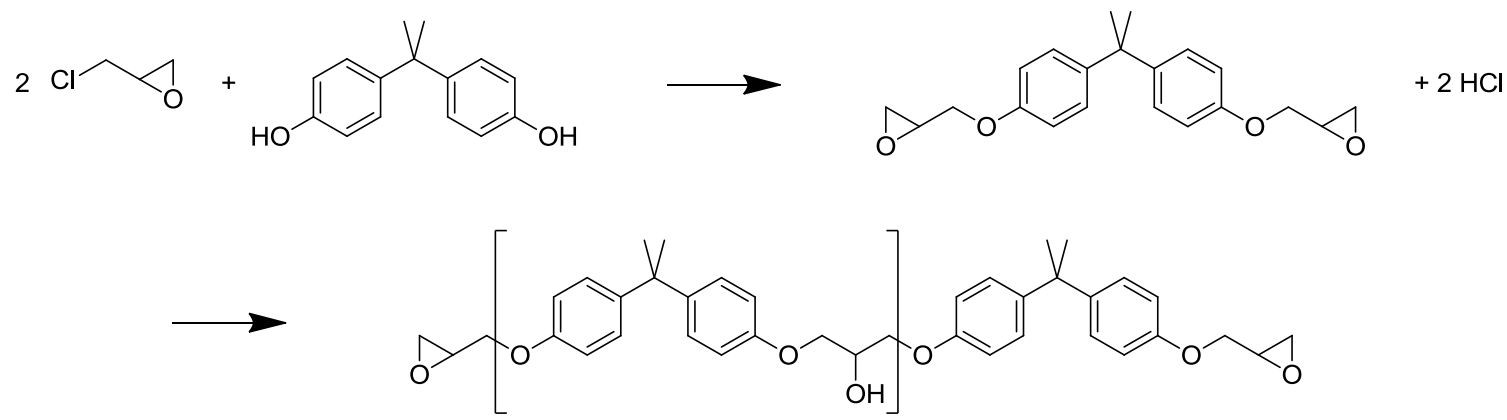

Figure 1.3.2. The synthesis of diglycidal ether of bisphenol $A$ and its formation into a family of epoxy prepolymers. ${ }^{14}$

A common amine curing agent used with epoxy resins are polyether amines (PEAs). As the backbones of these polyethers are flexible, a reduction of brittleness is imparted on the resulting thermoset, as well as increased impact resistance and elongation. ${ }^{15}$ Depending on the particular structure of the PEA, thermosets made from these materials can achieve more specific properties as well. For example, a low molecular weight trifunctional polyetheramine, such as the one shown in Figure 1.3.3 a, has use primarily in binder systems for composite materials due to the fact that when cured, the resulting thermoset matrix has a high crosslink density. ${ }^{16}$ A higher molecular weight polyetheramine, shown in Figure 1.3.3 b, has use primarily in waterborne epoxy coatings due to 
the hydrophilicity of these types of polymers and the lower crosslink density which results from its reaction with an epoxy resin. ${ }^{17}$

(a)

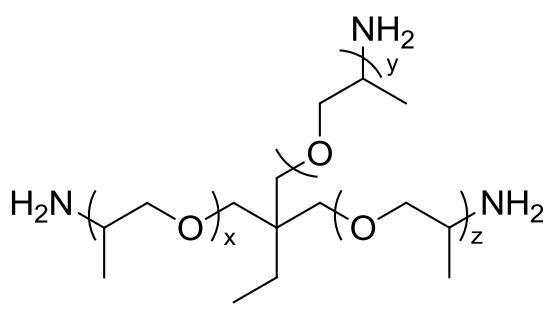

(b)<smiles>CC(C)COCC(C)OCC(C)OCC(C)C(C)N</smiles>

Jeffamine T-403

$\mathrm{mw}=440 \mathrm{~g} / \mathrm{mol}$

$x+y+z=5-6$

Figure 1.3.3. a) A trifunctional low molecular weight $(440 \mathrm{~g} / \mathrm{mol})$ polyetheramine (Jeffamine T-403) used primarily in composite resins. ${ }^{16}$ b) A difunctional mid range molecular weight $(2000 \mathrm{~g} / \mathrm{mol}$ ) polyetheramine (Jeffamine ED-2003) used primarily in water based epoxy coatings. ${ }^{17}$

The reactivity rate of epoxy resins with amine curing agents can also be tailored by adjusting the reactivity of the epoxy and amine groups. Adjusting the rate of the curing reaction can play a critical role in the processing of these thermosets. If the application of the thermoset requires that it reaches its ultimate state quickly, as is the case with certain fast acting adhesives, it is critical that the components react quickly, as would be the case with unhindered primary amines. If it is necessary for a material to have a longer processing time between component mixing and final application, then amines of the curing agent can be synthesized to be more hindered, decreasing their reactivity and thus increasing the pot life of the developing thermoset. Figure 1.3.4 shows a trend in amine hindrance and reactivity. ${ }^{18}$ 


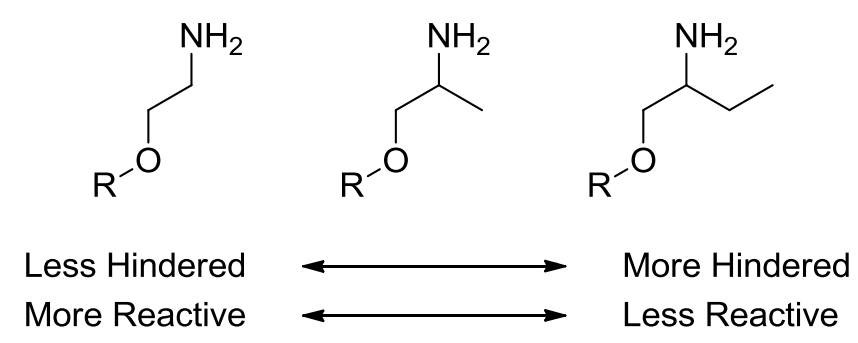

Figure 1.3.4. The relative reactivity of amine curing agents as a result of selective steric hinderence. ${ }^{18}$

Another common system used in the synthesis of thermoset materials uses polyurethane based chemistry. Polyurethane polymers and thermosets are synthesized from the reaction of isocyanates with alcohols, typically in the form of polyols (polymer chains which contain various degrees of alcohol functionality) in the presence of a catalyst. Isocyanates are also reactive with amines and water, which produces polyureas, and often the reaction with water yields a polyurethane foam. Catalysts for isocyanate reactions fall into two major groups, amines and organotin compounds. ${ }^{19}$ The type of catalyst used in the reaction depends on whether the isocyanate is to be reacted with polyols, amines or water. ${ }^{19}$ Amine catalysts are less active than organotin compounds and are used in the isocyanate reaction with amines and water because these reactants are more reactive than polyols. ${ }^{19}$ Organotin compounds are typically used for the reaction of isocyanates with polyols, which yields a polyurethane polymer or thermoset. Figure 1.3.5 shows the structure of a commonly used amine isocyanate catalyst, DABCO, (1,4-diaza-bicyclo-[2,2,2]-octane), and the general form of organotin catalyst compounds. ${ }^{19}$ 


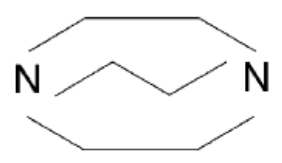

DABCO<smiles>[R2]C(=O)O[Sn]([R1])([R1])OC([R2])=O</smiles>

Organotin Compounds

Figure 1.3.5. Catalysts for the reaction between isocyanates and amines, water and polyols. ${ }^{19}$

Isocyanates are often used in prepolymer forms, as isocyanates are known to have toxic health effects which are minimized when they are in a prepolymer form which makes them non-volitile. These prepolymers are synthesized from the reaction of small molecule isocyanates with poly alcohols (polyols) to yield the prepolymer, as shown in Figure 1.3.6. These isocyanate terminated prepolymers may then be reacted with additional polyols, amines or even with water to yield the desired end product. ${ }^{20}$<smiles>O=C=Nc1ccc(Cc2ccc(N=C=O)cc2)cc1</smiles><smiles>CC(COC(=O)Nc1ccc(Cc2ccc(N=C=O)cc2)cc1)OC(=O)Nc1ccc(Cc2ccc(N=C=O)cc2)cc1</smiles>

Figure 1.3.6. The general synthesis of isocyanate polyurethane prepolymers. ${ }^{21}$ 
Polyurethane thermosets have properties similar to those of epoxy / amine thermosets, however they do display a higher degree of toughness than epoxy / amine systems. The specific properties of these systems are tailored by varying the composition of the polymer segments between the crosslinking points. ${ }^{22}$ Varying the composition of the polymers provides another means by which the strength and toughness of a material can be balanced in such a way as to optimize both. $^{22}$

A feature which is not necessarily unique to polyurethane materials, but is often observed in these materials, is a microphase separation of flexible, soft polymer containing segments and more rigid, urethane containing segments. This phase separation imparts elastomeric properties to polyurethane materials as well as increased thermostability. ${ }^{23}$ The degree of this phase separation, and the level to which the mechanical properties of the materials are enhanced occurs as a result of thermodynamic incompatibility of the chemistries of the copolymer segments. Each segments packing ability also plays a role in the development of enhanced properties, which can be affected by polyol chain type, molecular weight, and functionality, as well as hard isocyanate segment size and symmetry, allowing for proper hydrogen bonding. ${ }^{23}$

\subsection{Composite Materials}

Another method by which material properties can be tailored to meet particular requirements is through the inclusion of fillers which are able to impart new characteristics to the bulk thermoset or thermoplastic matrix. ${ }^{24}$ The 
advantage of the employment of composite materials over adjusting only the bulk polymeric phase of a material is that if designed correctly, the material will have the best qualities of both components rather than having to give up the advantages of one material property to make gains in another. ${ }^{24}$ As with polymeric materials, composites have been in use for thousands of years to the Israelites using straw in mud bricks to add strength, or the Japanese using laminated metals to create swords of the desired properties. ${ }^{24,25}$ Modern composites contain fillers which range from the macroscopic to micro and nano size. The most relatable macroscale composite used today is reinforced concrete, which contains steal rebar to add tensile strength, and rock aggregate to increase the compressive strength ${ }^{25}$ Composites on the micro and nano scale can be categorized into five major groupings: fiber, particulate, plate, skeletal, and laminar, shown in Figure 1.4.1. This paper focuses on the possible inclusion of fibrous, particulate, and platelike fillers into composite materials. Fibrous composites are used primarily to increase the tensile strength of materials, particulate composites act to increase the fracture toughness of the material, and plate like fillers add solvent / air barrier properties to the material. ${ }^{25}$ Examples of fibrous fillers include fibrous silica, materials composed of which have been used for decades and are commonly known as fiberglass; carbon fiber, and carbon nanotubes. Common particulate nanofillers include silica, alumina, polymeric nanoparticles, carbon black particles, and quantum dots. Platelike composite fillers are typically some sort of clay. ${ }^{25}$ 


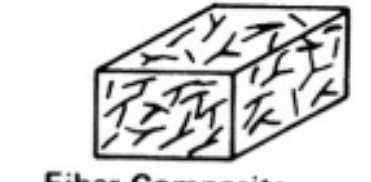

a)

Fiber Composite b)

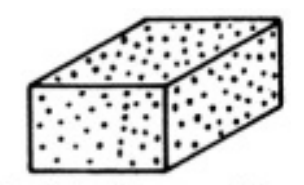

c)

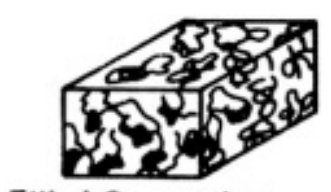

Filled Composite

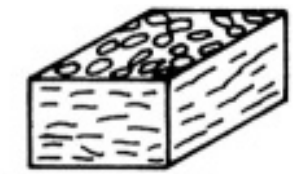

d) Flake Composite e)

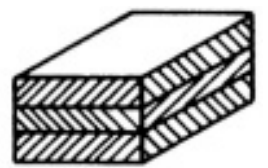

Figure 1.4.1. The general types of fillers found in modern micro and nano scale composites. Filled composites are also known as skeletal composites; flake composites are also known as plate like composites. ${ }^{25}$

\subsection{Dispersion of nanofillers}

The dispersion of nanofillers throughout a composite material plays a major role in the conveyance of the properties of both the filler and the matrix to the bulk properties of the composite materials. ${ }^{26}$ Nanoparticles included within a polymer matrix tend to aggregate as a result of depletion flocculation, and this aggregation can lead to non-uniform properties throughout the bulk of the material, which is typically an undesirable trait in a material. ${ }^{26}$ However, particle aggregation also tends to occur at surfaces due to reduction of total surface energy, which can provide a means by which to concentrate the effect of nanoparticles at the surface of a composite material where it may be the most effective, such as in fire retardant materials. ${ }^{27}$ The dispersion of composite nanoparticles can be controlled via the covalent tethering of matrix compatible polymer to the surface of the nanoparticles, this tether acts to make the nanoparticle thermally compatible with the matrix, as well as physically keep nanoparticles separated from one another. An atomic force micrograph of 
nanoparticle aggregation and dispersion as a result of polymer tethering is shown in Figure 1.5.1.
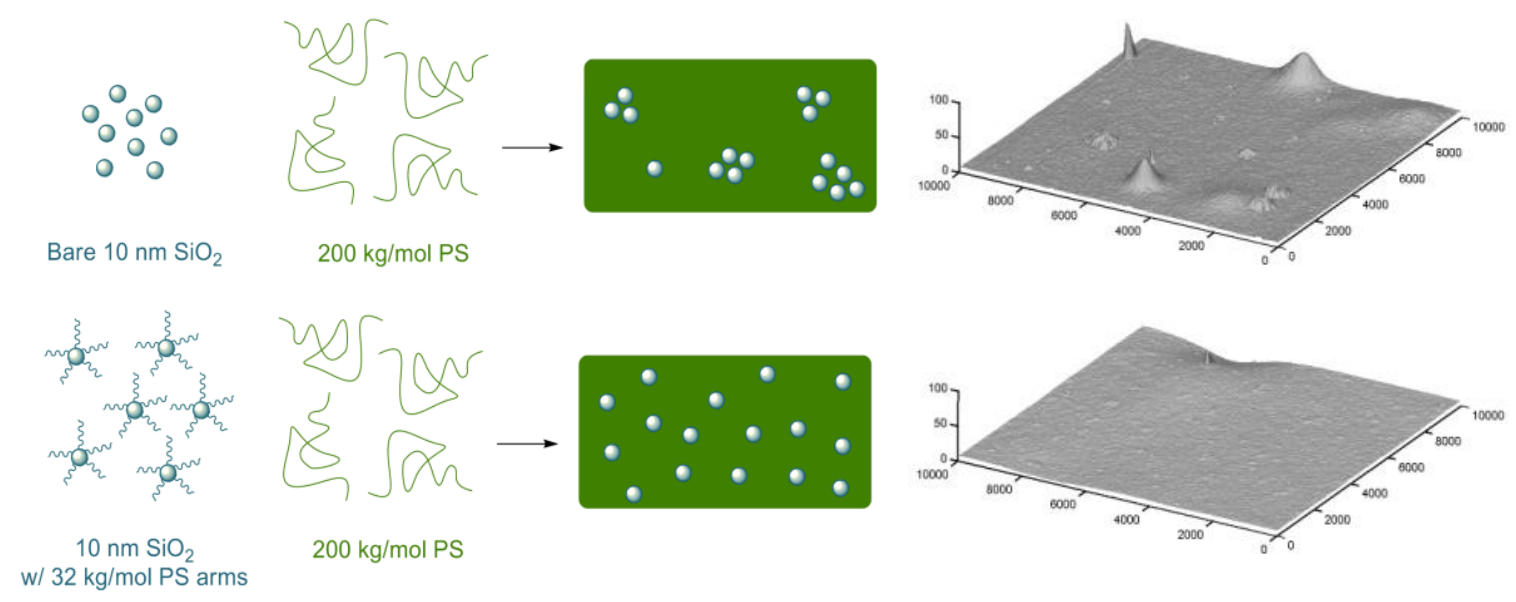

$200 \mathrm{~kg} / \mathrm{mol}$ PS
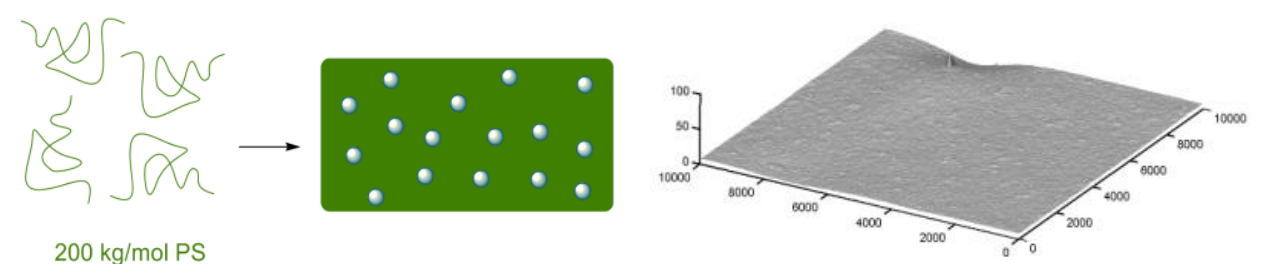

Figure 1.5.1. AFM depiction of aggregation and dispersion of silica nanoparticles in a polystyrene thermoplastic with and without a polymer tether. (Reproduced with permission from Dr. Daniel Savin)

The degree of dispersion of nanoparticles throughout a polymer matrix can be controlled by adjusting the length of the polymer tether which is attached to the nanoparticles surface. ${ }^{28}$ Nanoparticles with polymer tethers of higher molecular weight tend to be more disperse, while nanoparticles with polymer tethers of lower molecular weight tend to be less disperse. Figure 1.5.2 illustrates this concept and Figure 1.5.3 displays its application. ${ }^{28}$ 

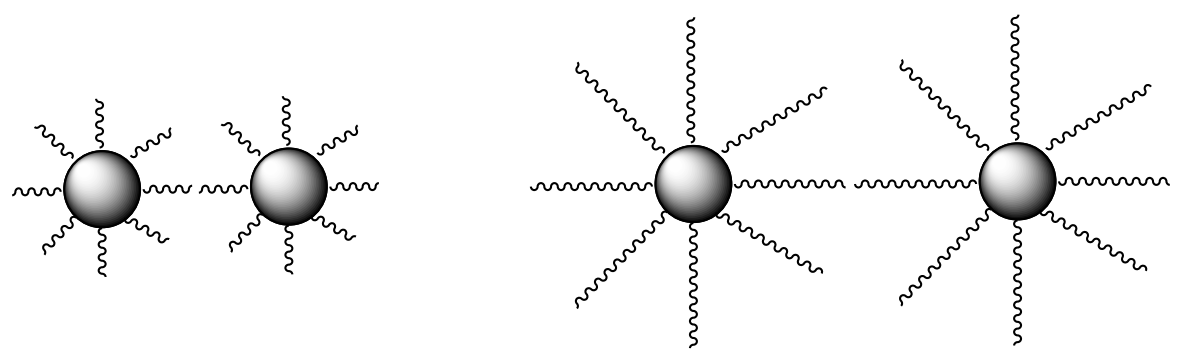

Lower Molecular
Weight Tether
Less Disperse

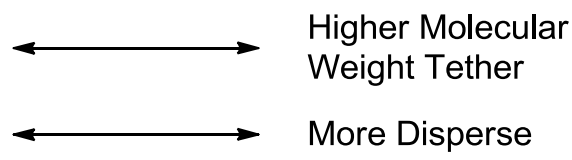

Figure 1.5.2. Schematic of the effect of polymer tether molecular weight on nanoparticle dispersion.

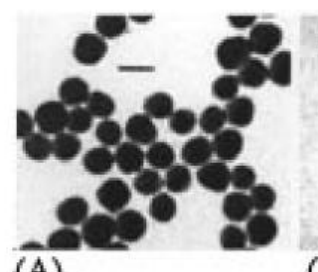

(A)
(B)

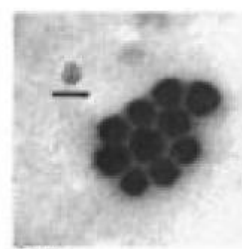

(C)

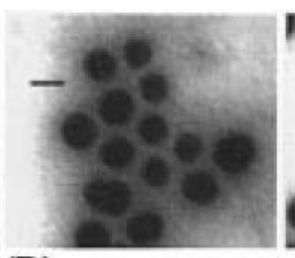

(D)

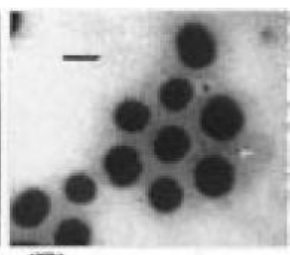

(E)

Figure 1.5.3. The dispersion of $\mathrm{SiO}_{2}$ nanoparticles (70nm diameter) as a function of the molecular weight of a polystyrene tether grafted from the surface of the nanoparticle via atom transfer radical polymerization (ATRP). Molecular weights of tethers are: $A=5400, B=9000, C=16800, D=24600, E=26500 .^{28}$

The tether which is bound to a nanoparticle can be composed of various types of polymers, depending on the composition of the matrix into which the nanoparticle is to be embedded. It has been shown that the location of nanoparticles within a biphasic polymeric material can be selected by tethering polymer to the nanoparticle surface which has greater thermodynamic compatibility with one of the polymer phases of the material ${ }^{29}$ The ability to trigger nanoparticle migration from one polymer phase of a material to another 
phase by eliciting a change in the thermodynamic nature of the polymer tether has also been demonstrated. ${ }^{30}$ This level of control of nanoparticle phase location suggests a means by which selective nanoparticle dispersion within a composite matrix can be introduced.

\subsection{Self Healing Materials}

Another means by which the fracture toughness and strength of a material can be controlled is through the inclusion of self healing properties in the bulk material. Self healing can be incorporated into a material by the inclusion of matrix raw materials throughout the composite which can then be triggered to react by a stimulus, resupplying the matrix with any material which may have been lost or displaced as a result of some sort of damage. ${ }^{31}$ These replenishing healing materials can be held within microcapsules or in a vascular network which can continually replenish the matrix material, progress towards the latter technique will be discussed is this thesis. ${ }^{32,33}$ Microencapsulation has been proven successful in systems using dicyclopentadiene (DCPD) and Grubbs' catalyst polymerization systems, shown in Figure 1.6.1. ${ }^{34}$ Though this system has proven to be successful, the cost effectiveness of these systems is not feasible for large scale materials due to the cost of the ruthenium based Grubb's catalyst. For this reason, there has been a transition to microencapsulation systems which utilize epoxy / amine healing agents. ${ }^{34}$ Additionally, the microencapsulation techniques only allow for a one time use of the microcapsules; once they are ruptured, the healing agent is gone forever. For this reason, there has been a transition into vascular systems which are based 
on the human cardiovascular system, which can continuously replenish healing agents; such a system is shown in Figure 1.6.2. ${ }^{34}$

(a)

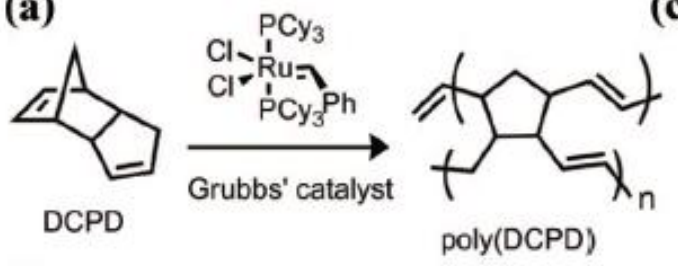

(b)

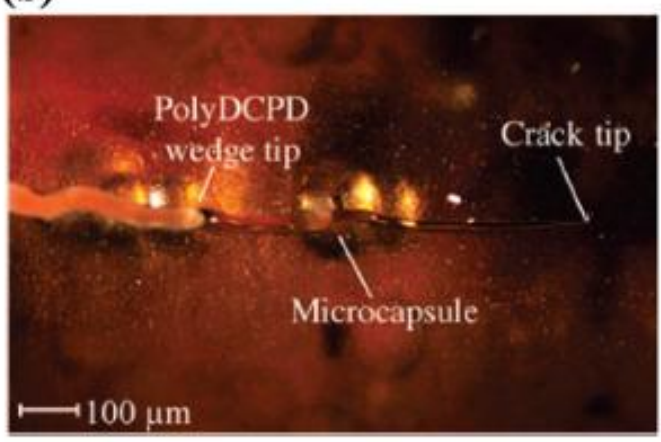

(c)

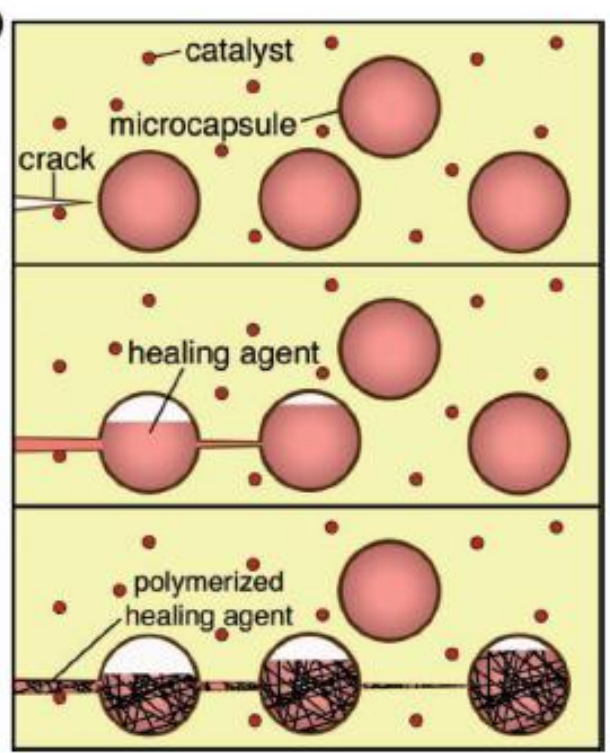

Figure 1.6.1. a) The polymerization of DCPD using Grubbs' catalyst. b) The healing of a crack with PolyDCPD which was polymerized from DCPD using Grubbs' catalyst released from ruptured microcapsules dispersed throughout the material. c) A schematic of the healing of a crack using healing agent released from microcapsules in a material. ${ }^{34}$

(a)

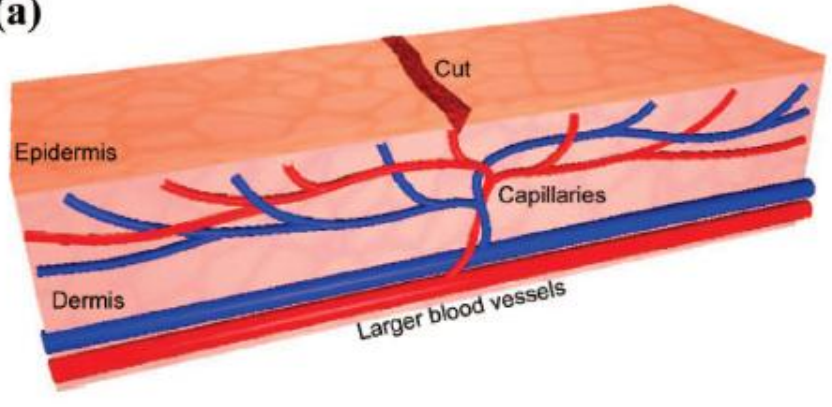

(b)

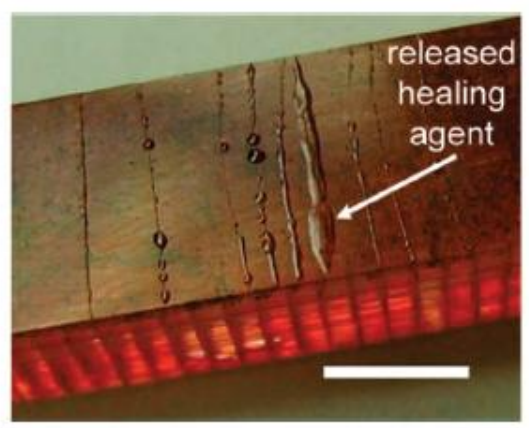

Figure 1.6.2. a) The cardiovascular system on which the biomimetic vascular self healing system is based. b) A self healing material which releases epoxy healing material from an artificial vascular network (scale bar $5 \mathrm{~mm}$ ) ${ }^{34}$ 
Another method by which self healing of a material can occur is through stimuli responsive reversible crosslinking of a thermoset composite material. This reversible crosslinking provides a means by which the stress applied to the thermoset by a crack can be dissipated by the temporary reversible cleavage at crosslink points rather than permanent cleavage of a covalent bond which leads to permanent damage to the thermoset composite. Once the stress from a fracture is dissipated, the crosslinks can reform, returning the composite to its original state. Synthesis of a variety of materials which may be applied toward this technique will be discussed further in this thesis. Varying the polymer composition of the matrix, the crosslink density and reversibility and the filler type and dispersion provide many tools by which materials can be tailored to maximize strength, toughness and permeability properties to improve corrosion resistance. 


\subsection{References}

(1) Nicholson, C. BSA Educational Services Committee Report 1991, 1.

(2) Brown, R. A. Journal of Chemical Education 1977, 54, 720.

(3) Marvel, C. S. Journal of Chemical Education 1981, 58, 535.

(4) Bowles, M. D.; Akron, U. o. Chains of opportunity: The University of Akron and the emergence of the polymer age, 1909-2007; The University of Akron Press, 2008.

(5) Hao, S. Bridge Structures - Assessment, Design \& Construction 2011, 7,3.

(6) Gerhardus H. Koch, M. P. H. B., Neil G. Thompson, Y. Paul Virmani, J.H. Payer Corrosion Costs and Preventive Strategies in the United States, 2002.

(7) Johnson, C. World Corrosion Organization Granted NGO status by the United Nations. [Online Early Access]. Published Online: 2010.

(8) Ralph M. Paroli, K. K. Y. L., Terrance R. Simmons Construction Technology Update 1999, 30

(9) Billmeyer, F. W. Textbook of polymer science; Wiley, 1984.

(10) Immergut, E. H.; Grulke, E. A.; Brandrup, J. Polymer handbook; Wiley: New York, 2008.

(11) Guo, Q.; Thomann, R.; Gronski, W.; Thurn-Albrecht, T. Macromolecules 2002, 35, 3133.

(12) Huang, Y.; Hunston, D. L.; Kinloch Anthony, J.; Riew, C. K. In Toughened Plastics l; American Chemical Society: 1993; Vol. 233, p 1.

(13) Jeenjitkaew, C., University of London, 2011.

(14) Bisphenol A Diglycidyl Ether Product Safety Assessment. The Dow Chemical Company: 2006.

(15) Kong, F.-M.; Walkup Connie, M.; Morgan Roger, J. In Epoxy Resin Chemistry II; AMERICAN CHEMICAL SOCIETY: 1983; Vol. 221, p 211.

(16) Jeffamine T-403 Technical Bulletin. Huntsman: 2007.

(17) Jeffamine ED-2003 Technical Belletin. Huntsman: 2007.

(18) David C. Alexander, B. L. B., Howard P. Klein; Huntsman Petrochemical Corporatio: 2005.

(19) Wegener, G.; Brandt, M.; Duda, L.; Hofmann, J.; Klesczewski, B.; Koch, D.; Kumpf, R.-J.; Orzesek, H.; Pirkl, H.-G.; Six, C.; Steinlein, C.;

Weisbeck, M. Applied Catalysis A: General 2001, 221, 303.

(20) Heintz, A. M.; Duffy, D. J.; Hsu, S. L.; Suen, W.; Chu, W.; Paul, C. W. Macromolecules 2003, 36, 2695.

(21) Ratna, D. Handbook of Thermoset Resins; Smithers Rapra Technology, 2009.

(22) Kaw, A. K. Mechanics of composite materials; Taylor \& Francis, 2006.

(23) Eceiza, A.; Larrañaga, M.; de la Caba, K.; Kortaberria, G.; Marieta, C.; Corcuera, M. A.; Mondragon, I. Journal of Applied Polymer Science 2008, 108, 3092. 
(24) Vinson, J. R.; Sierakowski, R. L. The behavior of structures composed of composite materials; Kluwer Academic Publishers, 2002.

(25) Erokhin, V.; Ram, M. K.; Yavuz, Ö. The new frontiers of organic and composite nanotechnology; Elsevier Science, 2008.

(26) Jenkins, P.; Snowden, M. Advances in Colloid and Interface Science 1996, 68, 57.

(27) Wang, X.; Hu, Y.; Song, L.; Xuan, S.; Xing, W.; Bai, Z.; Lu, H. Industrial \& Engineering Chemistry Research 2010, 50, 713.

(28) von Werne, T.; Patten, T. E. Journal of the American Chemical Society 1999, 121, 7409.

(29) Chiu, J. J.; Kim, B. J.; Yi, G.-R.; Bang, J.; Kramer, E. J.; Pine, D. J. Macromolecules 2007, 40, 3361.

(30) Costanzo, P. J.; Beyer, F. L. Macromolecules 2007, 40, 3996.

(31) Esser-Kahn, A. P.; Odom, S. A.; Sottos, N. R.; White, S. R.; Moore, J. S. Macromolecules 2011, 44, 5539.

(32) Mcllroy, D. A.; Blaiszik, B. J.; Caruso, M. M.; White, S. R.; Moore, J. S.; Sottos, N. R. Macromolecules 2010, 43, 1855.

(33) Toohey, K. S.; Sottos, N. R.; Lewis, J. A.; Moore, J. S.; White, S. R. Nat Mater 2007, 6, 581.

(34) Caruso, M. M.; Davis, D. A.; Shen, Q.; Odom, S. A.; Sottos, N. R.; White, S. R.; Moore, J. S. Chemical Reviews 2009, 109, 5755. 


\section{Controlling Surface Energy and Wetability with Diels-Alder Chemistry}

\subsection{Introduction}

The functionalization of the interior surfaces of vascularized structural materials using reversible Diels-Alder linkages was investigated as a possible means in the development of self healing materials. This work was done in collaboration with $\mathrm{Dr}$. Joshua Orlicki, and Dr. Eric Wetzel at the Army Research Laboratory, and with Philip Dirlam at California Polytechnic State University in San Luis Obispo. Initial synthetic work was performed at the Army Research Laboratory by Phil Dirlam under the supervision of Dr. Orlicki and Dr. Wetzel. The syntheses of the surface treatments were then optimized and tested at California Polytechnic State University in San Luis Obispo. Testing methods including contact angle measurements of funtionalized glass slides, and flow impediment of patterned glass capillaries. This work was previously published (Langmuir 2009, 26, 3942) and is attached as Appendix A. 


\section{Responsive Matrix and Nanofillers via Diels-Alder Chemistry}

\subsection{Introduction}

In recent years, the incorporation of nanosilica particles to enhance the properties of epoxy based resin sustems has been explored for the development of materials to be used in the engineering applications of the future. ${ }^{1-3}$ The inclusion of these silica nanoparticles in such nanocomposite materials acts to increase the fracture toughness, ductility, and modulus of the virgin epoxy thermoset resins. ${ }^{4}$ The mechanisms by which these increased physical and mechanical properties are bestowed upon these nanocomposite materials is not entirely understood; however, many theories of the mechanisms exist such as crack deflection theory by Faber and Evans, crack pinning theory by Lange, Evans and Green; debonding and plastic void growth theory by Evans, Huang and Kinloch, and particle pull-out and microcracking. ${ }^{4}$ In addition to these fracture toughening mechanisms, the mobility of nanofillers within a polymer matrix which is controlled by entropy, can play an equally critical role in the enhancement of fracture toughness of the nanocomposite material. ${ }^{5}$

The entropy driven mobility of nanofillers within a polymer matrix has shown a preferential migration of nanoparticles to cracks, a feature which could potentially be exploited to provide a mechanism for self healing materials. ${ }^{5}$ As cracks develop in polymeric nanocomposite materials, the material initially undergoes the formation of a craze, the precursor to the formation of a crack, shown in Figure 3.1.1. The rate and ease of craze formation and propagation 
ultimately leads to the macroscopic strength and toughness of polymeric nanocomposite materials. ${ }^{5}$

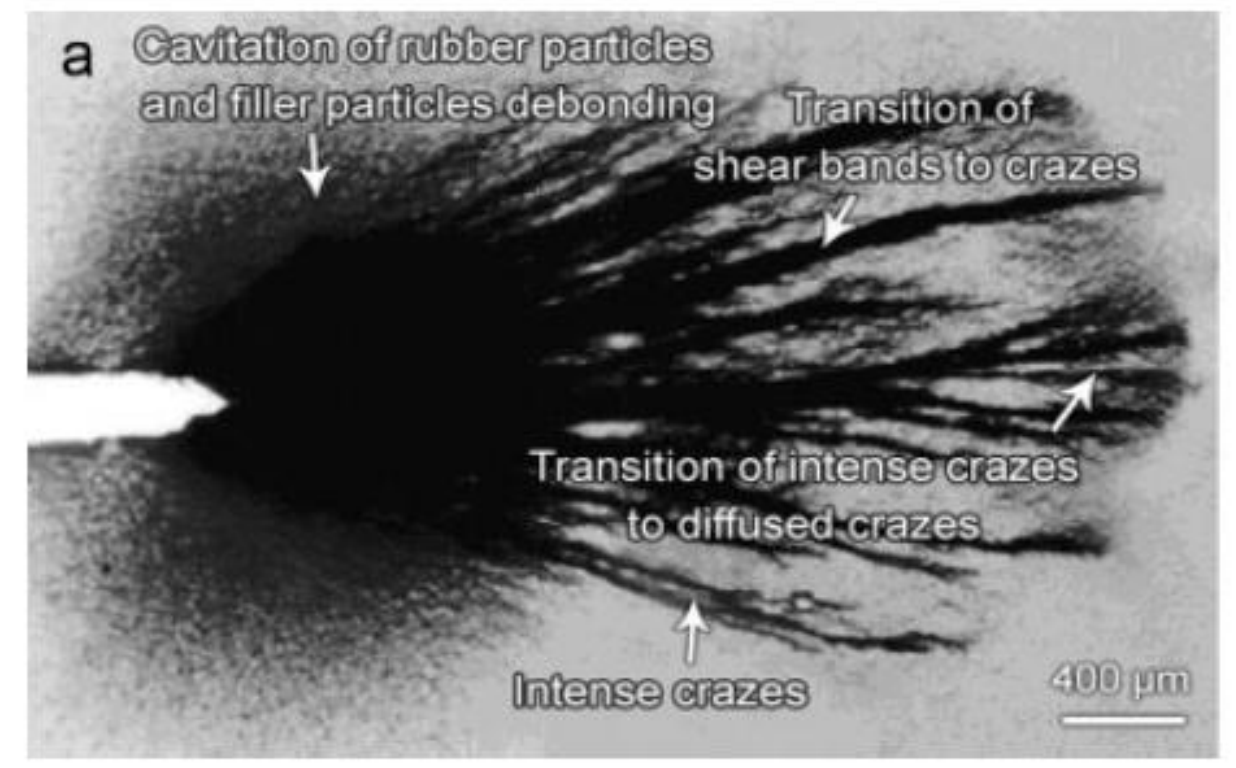

Figure 3.1.1. Transmitted optical microscopy of crack tip damage zone in a polypropylene / $15 \mathrm{wt}$. $\% \mathrm{CaCO}_{3}$ nanocomposite depicting craze formation. ${ }^{1}$

Craze formation occurs ahead of the crack tip as a result of stress and/or strain on a material causing the polymeric material to form an array of nanoscale fibrils (5-30 nm in diameter). ${ }^{5}$ Crazes form in four phases, precraze, premature craze, transitional craze, and mature craze ${ }^{5}$ When nanofillers are present in a polymeric matrix, craze formation is retarded by the entropic interactions between the polymer chains in the material and the nanofillers. This causes craze formation to occur in a different fashion than in virgin polymeric material, as shown in Figure 3.1.2 and 3.1.3. 


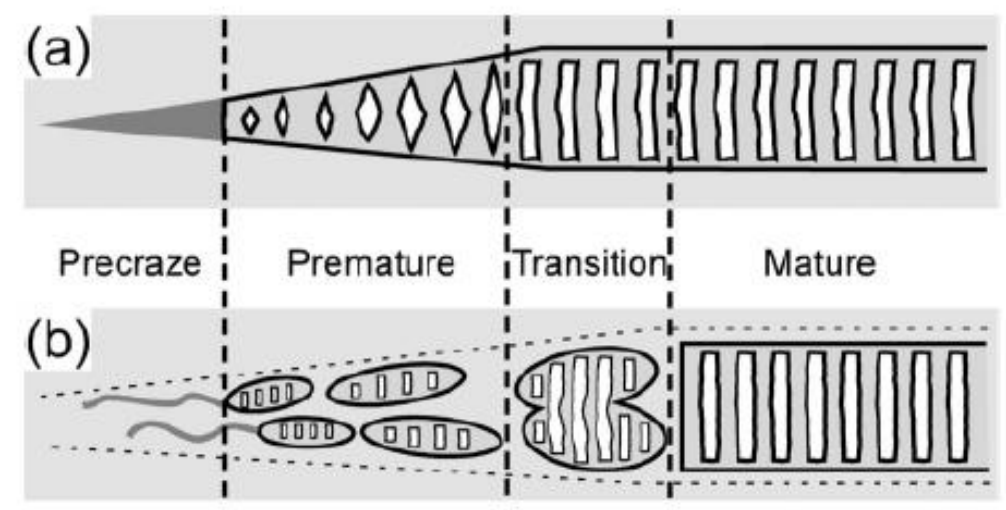

Figure 3.1.2. Schematic representation of the formation of a craze in both an (a) virgin polymeric matrix, and a (b) polymer nanocomposite matrix. ${ }^{5}$
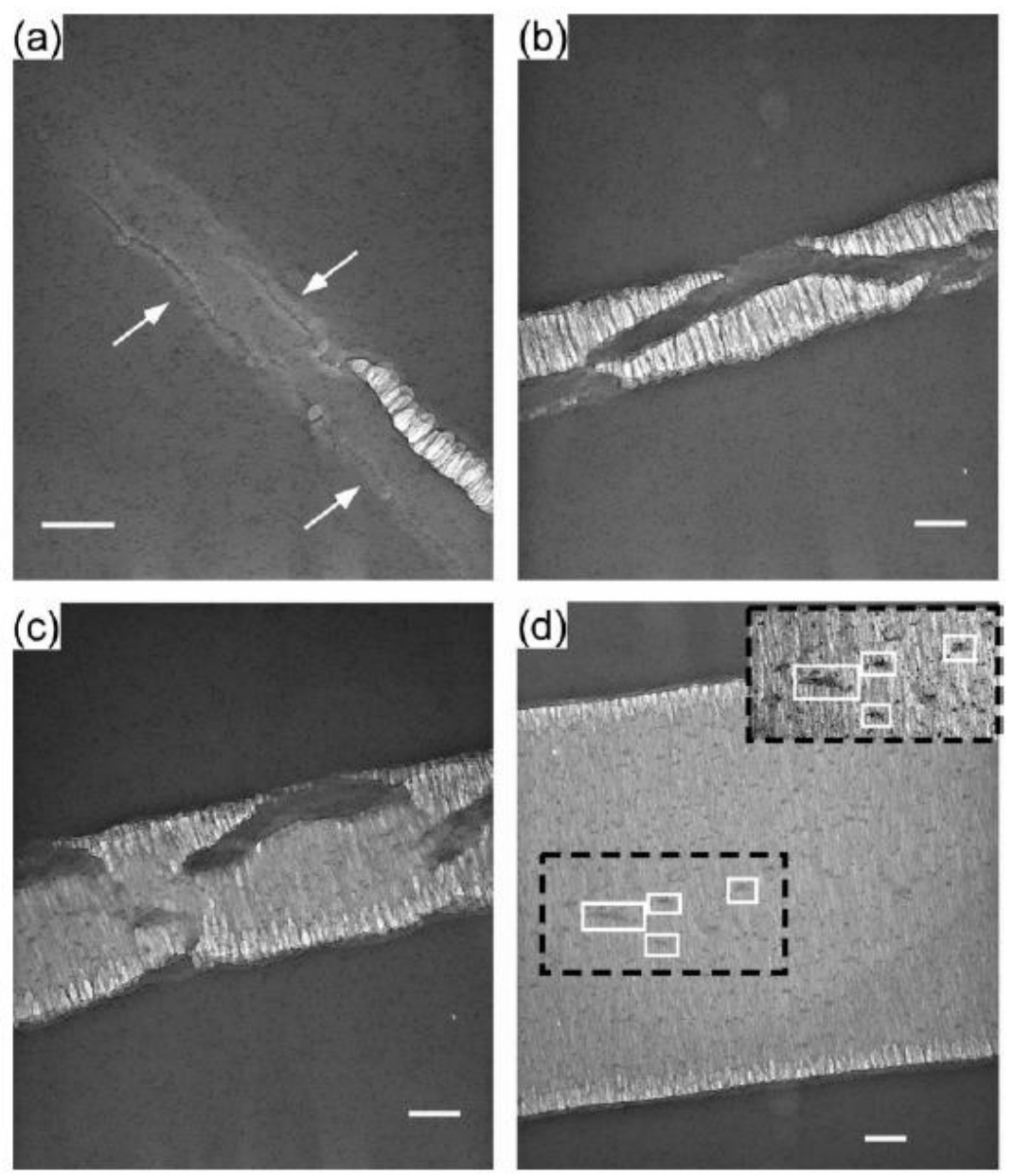

Figure 3.1.3. Transmission electron micrograph (TEM) of polymer nanocomposite showing stages of (a) precraze, (b) premature, (c) transition, and (d) mature regions. The lining up of nanoparticles can be seen along the precraze and the aggregation of nanoparticles can be seen in the mature craze. ${ }^{5}$

(Scale bar is $200 \mathrm{~nm}$ ) 
As craze formation occurs, at the tip of the forming craze (the precraze) the polymers in the matrix become more mobile and act somewhat fluid like, allowing for easier migration of nanoparticles to the center of the forming precraze, as seen in Figure 3.1.4. ${ }^{5}$ The increased ease of migration of nanoparticles through polymeric matrices of greater molecular mobility has been shown previously by Costanzo et. al. ${ }^{6}$ In addition to varying the degree of mobility of the polymeric matrix, the degree of aggregation of nanoparticles within polymeric nanocomposites has also shown to be a possible means by which to increase the fracture toughness of nanocomposite materials. ${ }^{7}$
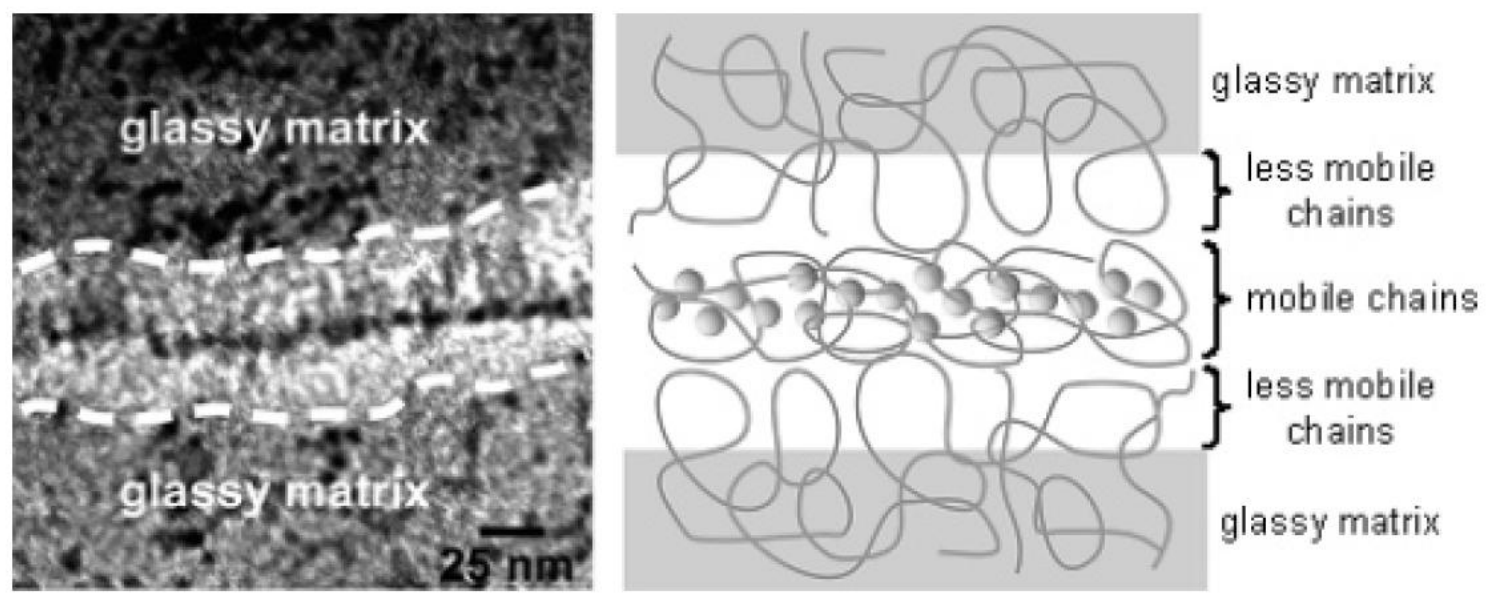

Figure 3.1.4. TEM and corresponding Scheme of the the preferential migration of nanoparticles to the precraze in a polymer nanocomposite. ${ }^{5}$

A combination of control of the mobility of the polymer matrix of nanocomposite materials with the degree of aggregation of nanoparticles within a matrix can provide an additional level of control of physical and mechanical properties of nanocomposite materials. Glass-like epoxy thermoset matrix composites are composed of highly immobile polymeric phases due to the 
crosslinking density of the system. ${ }^{8}$ A method by which mobility in these glasslike epoxy matrices can be provided is by making the crosslink sites of the thermoset reversible, thus changing the rheological properties of the material. ${ }^{9}$

\subsection{Experimental Approach}

In order to develop a crosslinked, thermoset matrix to be used in nanocomposite materials which allows for increased nanoparticle mobility in regions of matrix, leading to increased fracture toughness, it is proposed that reversible thermally responsive Diels-Alder linkages be incorporated into the matrix of such nanocomposite materials. The Diels-Alder reaction has been used previously as a thermally responsive linker, according to the reversible reaction shown in Figure 3.2.1. ${ }^{10}$

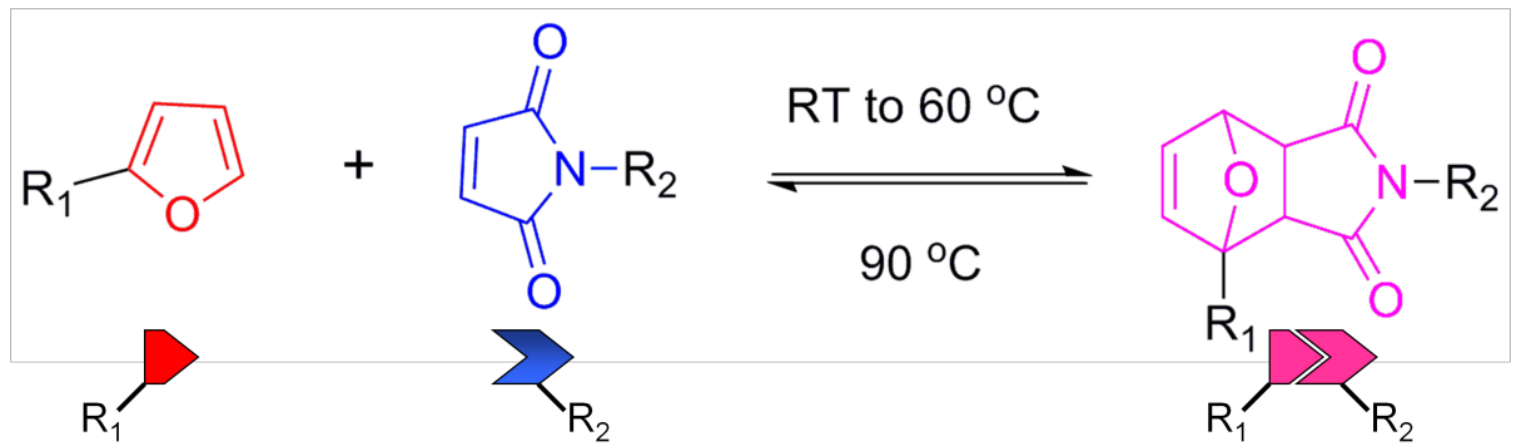

Figure 3.2.1. Reversible Diels-Alder adduct whose formation is temperature dependent. Red - Diene, Furan. Blue - Dienophile, Maleimide.

Multiple Schemes were designed in order to include these Diels-Alder linkages into both the epoxy resins and amine curing agents. In both cases, the resulting reversibly crosslinked matrix should provide the ability to transition from a thermoset to a thermoplastic material allowing for nanoparticle migration as 
depicted in Scheme 3.2.1. The different materials and methods employed in the following Schemes were intended to allow for modification of both the reversible and permanent crosslink density of the resulting thermosets.

Scheme 3.2.1. Schematic representation of the utilization of a reversibly crosslinkable thermoset matrix in the enhancement of nanoparticle migration. Particle mobility within DA functionalized matrix. Left to Right : Base material; application of heat; cleave of DA linkages; particle migration; reformation of DA linkages.
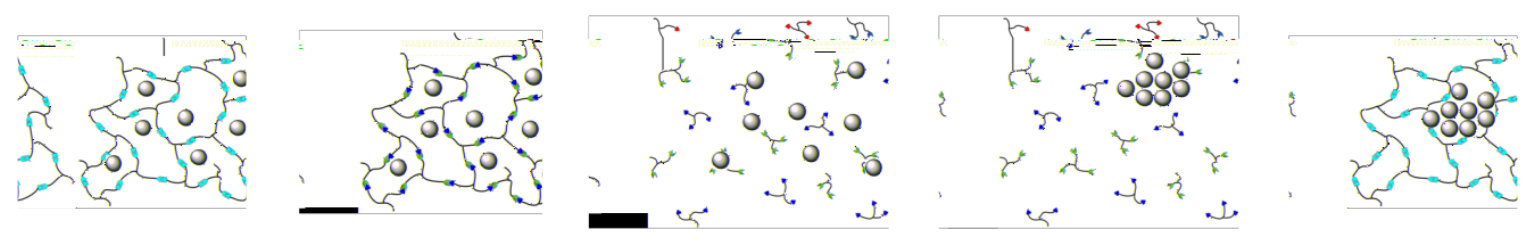

\subsubsection{Diels-Alder Linkage Optimization}

As shown in Figure 3.2.1, variation of the $\mathrm{R}$ groups adjacent to the diene and dienophile utilized in the Diels-Alder linkage varies the temperature range at which the forward and retro Diels-Alder reaction occur. For this reason, many different dienes and dienophiles were synthesized, including variations of furan dienes, fulvene dienes, maleimide dienophiles and other electron deficient dienophiles via Knoevenagel condensation. Ultimately, the dienes chosen were furfuryl alcohol altered with succinic anhydride (compound 1) and Boc-protected furfuryl amine (compound 2), these compounds are shown in Scheme 3.2.2. The dienophiles chosen were both conjugated aromatic maleimides, one with a carboxylic acid group in the para position(compound 3), and one with a para position phenol group (compound 4), shown in Scheme 3.2.3 (a) and (b) respectively. 
Scheme 3.2.2. Synthesis of dienes used in Diels-Alder linkages. (a) Succinic anhydride modified furfuryl alcohol, (b) Boc protected furfuryl amine.

(a)<smiles>OCc1ccco1</smiles>

(b)<smiles>NCc1ccco1</smiles><smiles>O=C1CCC(=O)O1</smiles>

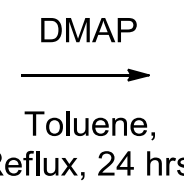<smiles>O=C(O)CCC(=O)OCc1ccco1</smiles>

1<smiles>CC(C)(C)OC(=O)NCc1ccco1</smiles>

Scheme 3.2.3. Synthesis of dienophiles used in Diels-Alder linkages.

(a)<smiles>Nc1ccc(C(=O)O)cc1</smiles>

1) Maleic anhydride, Acetone, RT, 4 hrs.

2) Acetic anhydride, $\mathrm{NaOAc}, \mathrm{DMF}, 70^{\circ} \mathrm{C}, 4 \mathrm{hrs}$<smiles>O=C(O)c1ccc(N2C(=O)C=CC2=O)cc1</smiles>

3

1) Maleic anhydride, Acetone, RT, 4 hrs.

(b)<smiles>Nc1ccc(O)cc1</smiles>

2) $\mathrm{P}_{2} \mathrm{O}_{5}, \mathrm{H}_{2} \mathrm{SO}_{4}$, DMF, $70^{\circ} \mathrm{C}, 24 \mathrm{hrs}$.<smiles>O=C1C=CC(=O)N1c1ccc(O)cc1</smiles>

4 


\subsubsection{Amine Curing Agent Modificaiton}

In order to utilize both types of dienophiles known to successfully undergo the forward and retro Diels-Alder reaction, as well as develop crosslinked thermoset matrices which would display variability in physical properties, two schemes were employed. The first scheme utilized polydimethylsiloxane modification with compound 4 , while the second technique utilized a common industrial amine curing agent, Huntsman Jeffamine polyetheramines with compound 3.

3.2.2.1 Polydimethylsiloxane Modification

Polydimethylsiloxane was used as its chlorosilane form for its high reactivity in order to ensure the reaction between the chlorosilane group and the electron deficient phenol group of compound 3. The preparation of the polydimethylsiloxane modified amine curing agent is shown in Scheme 3.2.4. 
Scheme 3.2.4. The synthesis of Diels-Aleder modified polydimethylsiloxane.<smiles>C[Si](C)(Cl)O[Si](C)(C)O[Si](C)(C)O[Si](C)(C)Oc1ccc(N2C(=O)C=CC2=O)cc1</smiles>

Compound 2,

THF, RT, 48 hrs.<smiles>CC(C)(C)OC(=O)NCC12C=CC(O1)C1C(=O)N(c3ccc(O[Si](C)(C)O[Si](C)(C)Oc4ccc(N5C(=O)C6C7C=CC(CNC(=O)OC(C)(C)C)(O7)C6C5=O)cc4)cc3)C(=O)C12</smiles><smiles>[3H][Si](C)(Oc1ccc(N2C(=O)C3C4C=CC(CN)(O4)C3C2=O)cc1)O[Si](C)(C)Oc1ccc(N2C(=O)C3C4C=CC(CN)(O4)C3C2=O)cc1</smiles>

3.2.2.2 Jeffamine Polyetheramine Modification

The use of a common commercially available amine curing agent was selected in that it is desirable to keep current manufacturing processes as constant as possible, with adding a small modification, if such fracture toughness modifications are proven to be industrially feasible. Huntsman Jeffamine amine terminated polyethers are available in a wide variety of backbone polyether types, molecular weights, degrees of functionality and rates of reactivity. Two types of Jeffamines were chosen for modification: Jeffamine T-403, a low 
molecular weight (440 g/mol), polypropyleneoxide (PPO) based backbone trifunctional polyetheramine Figure 3.2.2 (a); and Jeffamine ED-2003, a medium molecular weight $(2000 \mathrm{~g} / \mathrm{mol})$, polyethyleneoxide (PEO) / PPO based backbone difunctional polyetheramine Figure 3.2.2.(b). The technique employed in the modification of the Jeffamine polyetheramine polymers was the same for both the Jeffamine T-403 and the Jeffamine ED-2003, Scheme 3.2.5 shows the modification technique as it is employed for Jeffamine T-403.

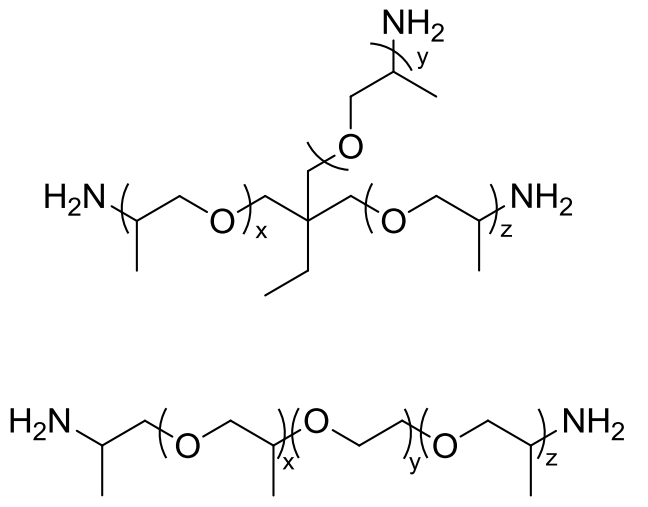

Jeffamine T-403

$\mathrm{mw}=440 \mathrm{~g} / \mathrm{mol}$

$x+y+z=5-6$

Figure 3.2.2. Huntsman Jeffamine amine terminated polyethers. 
Scheme 3.2.5. Synthesis for Diels-Alder modification of Jeffamine T-403. (R groups are same as top amine functionalization).<smiles>CCC(COCC(C)N)(COCC(C)N)C(=O)OCC(C)(C)N</smiles>

1) Compound 3 , oxalyl chloride, $\mathrm{CH}_{2} \mathrm{Cl}_{2}$, cat. DMF, RT, 2 hrs.

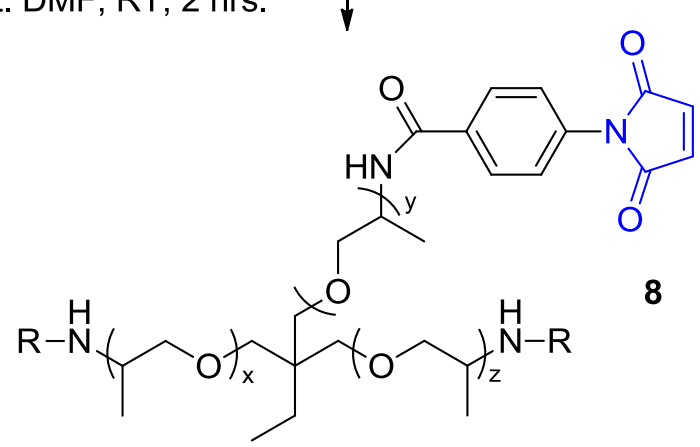

$$
\begin{aligned}
& \text { Compound 2, } \\
& \text { THF, RT, } 48 \text { hrs. }
\end{aligned}
$$<smiles>[R]NC(C)COCC(C)C(CC)(CC)COCC(C)NC(=O)c1ccc(N2C(=O)C3C4C=CC(CNC(=O)OC(C)(C)C)(O4)C3C2=O)cc1</smiles><smiles>[R]NC(C)COCC(CC)(CC)C(CC(C)COCC(C)NC(=O)c1ccc(N2C(=O)C3C4C=CC(CN)(O4)C3C2=O)cc1)OCC(C)N[R]</smiles> 


\subsubsection{Epoxy Resin Modification}

As with the modification of amine curing agent polymers, epoxy resins were chosen to allow the utilization of both types of dienophiles to investigate variability in acquired properties. The materials chosen to modify were commercially available bisphenol A based EPON 828 epoxy resin, and in an attempt to develop a new, green epoxy resin with increased fracture resistant properties, soy-bean oil was modified with Diels-Alder linkages.

\subsubsection{EPON Epoxy Resin Modification}

EPON epoxy resin was chosen to be modified due to its common use in current industrial processes. Scheme 3.2.6 shows the method by which a generic bisphenol A based EPON epoxy resin is to be modified. 
Scheme 3.2.6. Synthesis of Diels-Alder modified EPON epoxy binder. ( $R$ groups are same as right side epoxy functionalization).

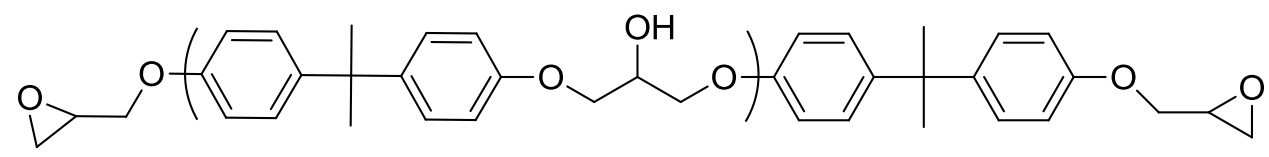

Compound 3,

Toluene, Reflux $24 \mathrm{hrs}$.
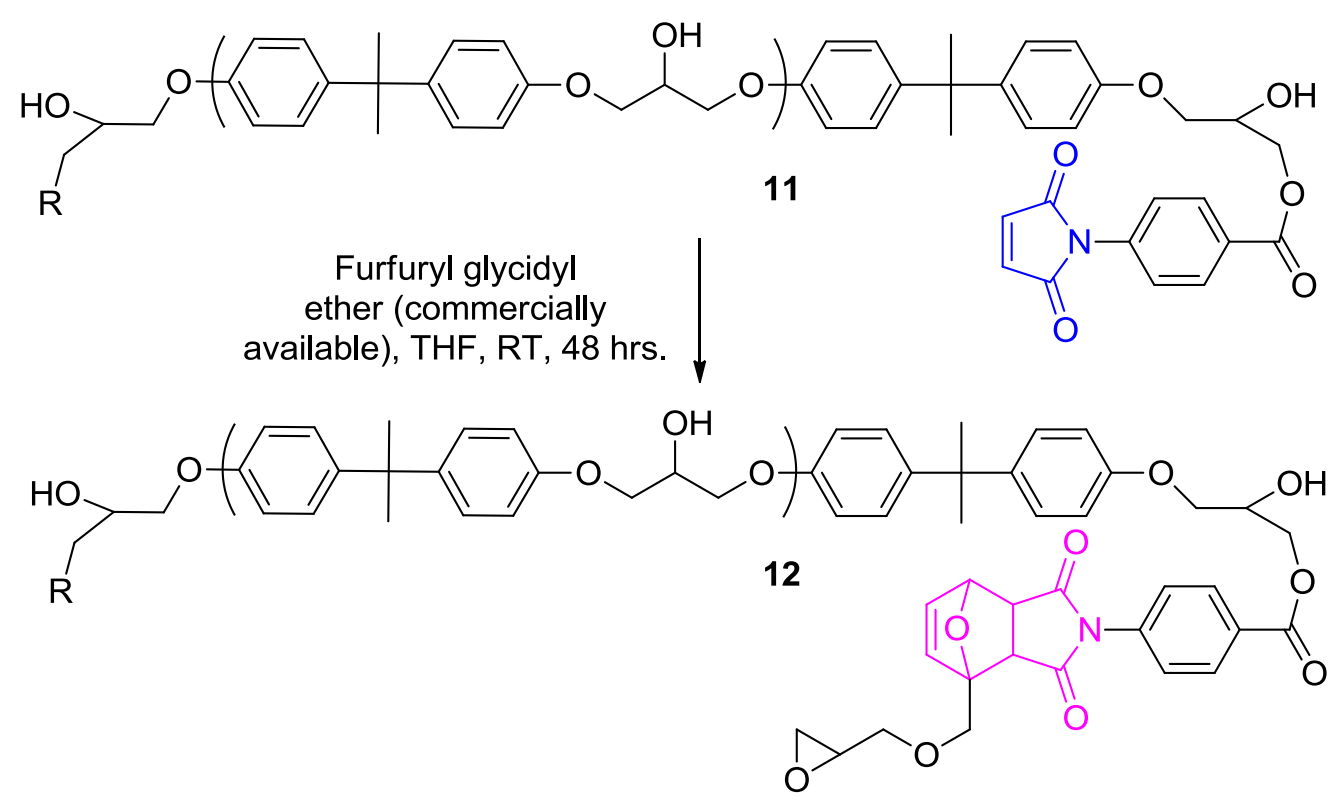

\subsubsection{Soy-Bean Oil Modification}

In an attempt to develop a novel, biobased responsive thermoset material, soy-bean oil was employed as a base material. Soy-bean oil, as with other biologically extracted fatty oils, is a triglyceride containing a mixture of fatty acids, the amounts of these fatty acids present in soy-bean oil are shown in Figure 3.2.3. ${ }^{11}$ The method by which extracted soy-bean oil is transformed into an epoxy binder is shown in Scheme 3.2.7. In this Scheme the soy-bean oil is first epoxided, which has been used in the past as a non-thermally responsive epoxy resin. ${ }^{11}$ 
(a)<smiles>[R]OCC(COC(=O)CCCCCCC/C=C\C/C=C\CCCCC)O[R]</smiles><smiles>CCCC=CCC=CCC=CCCCCCCCC(=O)O</smiles>

Figure 3.2.3. (a) The general triglyceride form of fatty oils extracted from biological sources. (b) The fatty acid $\mathrm{R}$ group distribution which occurs in soybean oil. One of the $\mathrm{R}$ groups is shown as linoleic acid in this Figure and in the following Schemes as it is the most prevalent fatty acid foud in soy-bean oil

The arm shown in the Schemes is linoleic acid as it makes up the largest percentage of soy-bean oil, the R groups shown are any of the fatty acids which are present in soy-bean oil triglycerides, no matter what the fatty acid, any alkene groups present are ultimately converted into epoxides and subsequently into Diels-Alder linkages with a phenol terminous. 
Scheme 3.2.7. The modification of soy-bean oil into a thermally responsive epoxy resin containing reversible Diels-Alder linkages. (Reactions are shown for linoleic acid as it is the most prevalent fatty acid.)
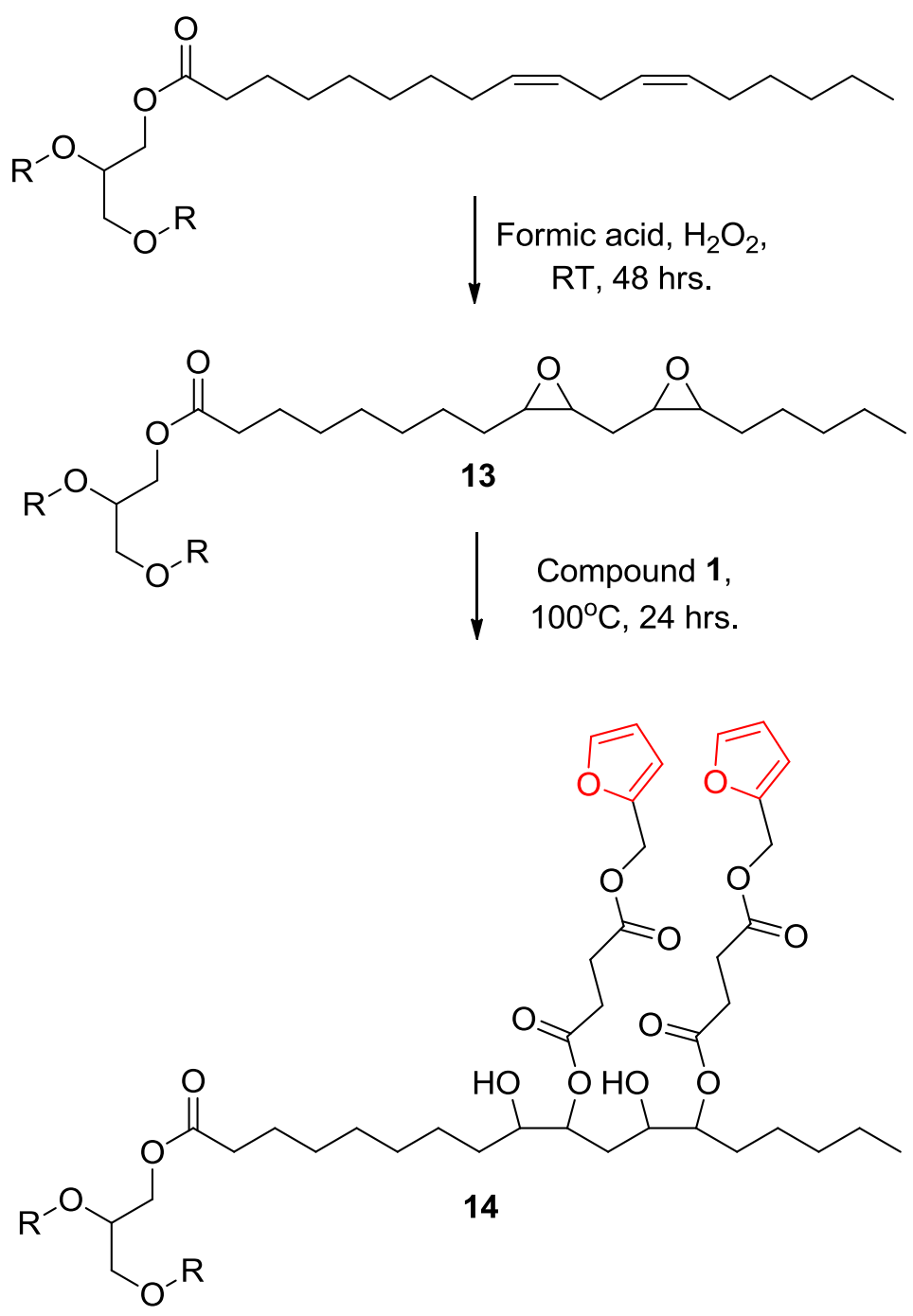

Once the diene is incorporated into the soy-bean oil, as shown in compound 14 in Scheme 3.2.7, there are a number of ways in which the polymer can then be altered. The techniques which were investigated are as follows: the alcohols resulting from the opening of the epoxide were left alone and the dienes were reacted with compound 4 (Scheme 3.2.8); the alcohols were acetylated with 
acetic anhydride prior to the Diels-Alder reaction between the dienes and compound 4 (Scheme 3.2.9); the alcohols can be reacted with acid halide functionalized compound $\mathbf{1}$ which can then be reacted with various diene:dienophile (compound 4) ratios (Scheme 3.2.10). The employment of these Schemes allows for control over the degree of crosslink density, both reversible and permanent, which will be present in the thermoset matrices which result from curing these modified soy-bean oils with some crosslinking agent.

Scheme 3.2.8. Resulting compound from reaction of compound 14 with compound 4 in THF for $48 \mathrm{~h}$.

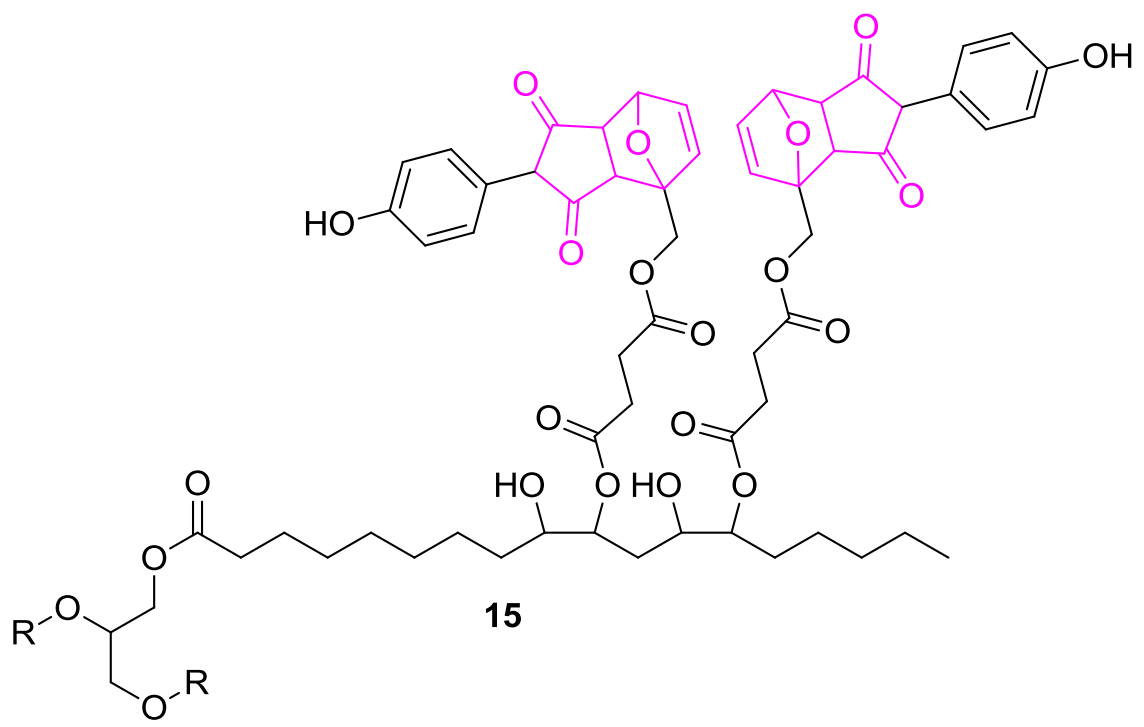


Scheme 3.2.9. Resulting compound after acetylation of using acetic anhydride, $\mathrm{Et}_{3} \mathrm{~N}$, in THF at $60^{\circ} \mathrm{C}$ for $24 \mathrm{~h}$ Followed by the reaction with compound 4 in THF at RT for $48 \mathrm{~h}$

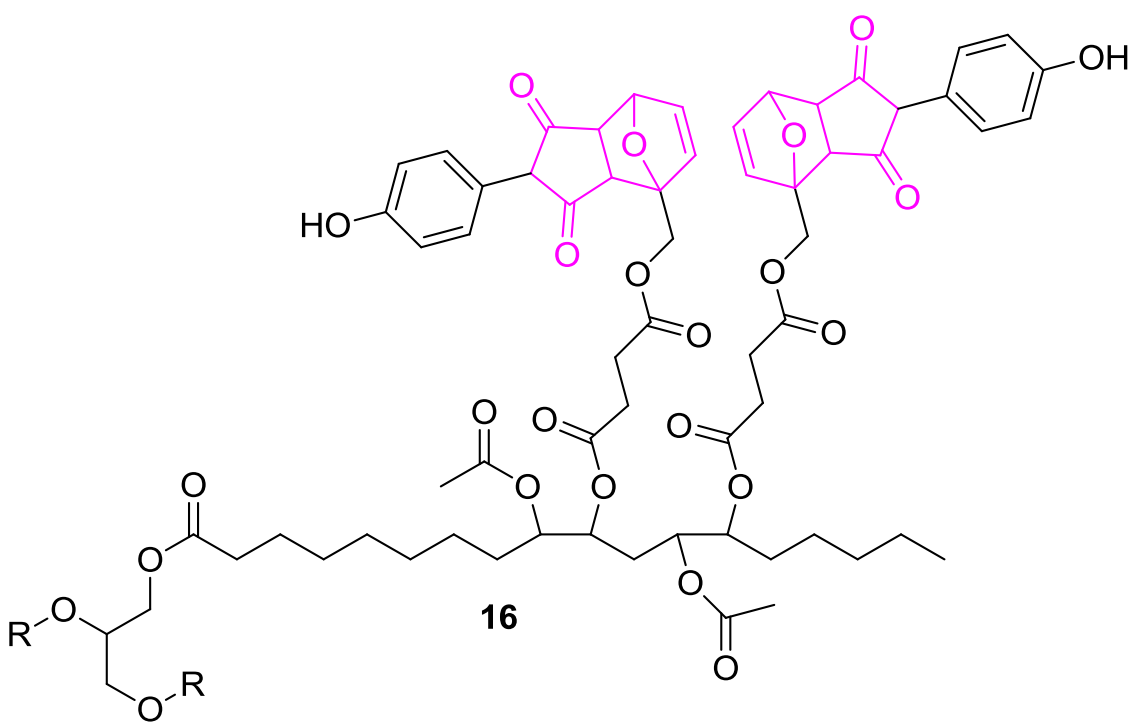

Scheme 3.2.10. Resulting compound from the reaction of compound 14 with compound 1 which has been treated with oxalyl chloride in $\mathrm{CH}_{2} \mathrm{Cl}_{2}$ with catalytic DMF, followed by the reaction with compound 4 in THF at RT for $48 \mathrm{~h}$

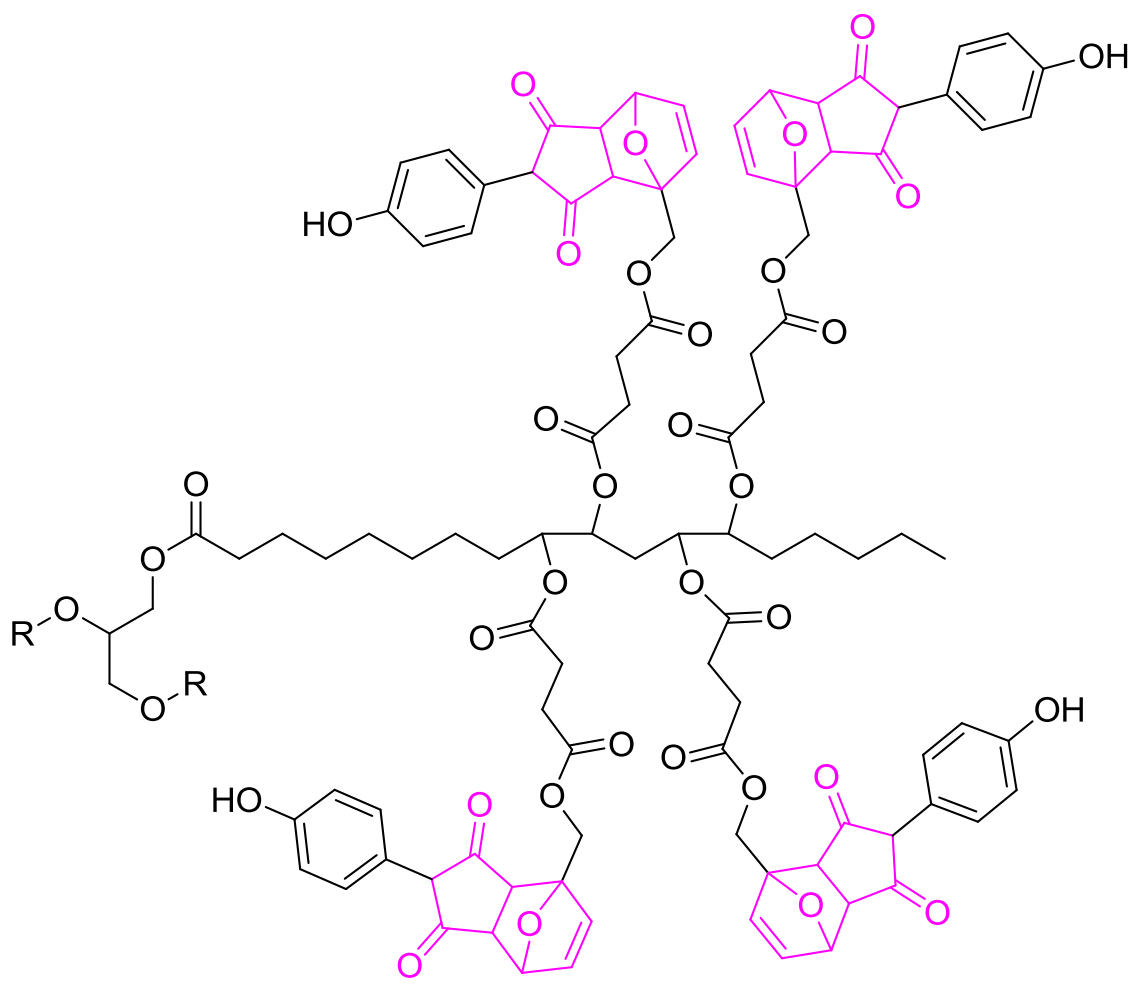


The three compounds $(15,16$, and 17$)$ resulting from the reaction of the diene functionalized soy-bean oil with compound $\mathbf{4}$ can then be used to react with isocyanate polymers to yield a reversibly crosslinked thermoset matrix, or can be reacted with commercially available epichlorohydrin to yield the desired epoxy resin containing the reversible Diels-Alder linkages, an example is shown in Scheme 3.2.11 with the base compound 15 material.

Scheme 3.2.11. Synthesis of thermally responsive epoxy resin using compound 15 and epichlorohydrin.

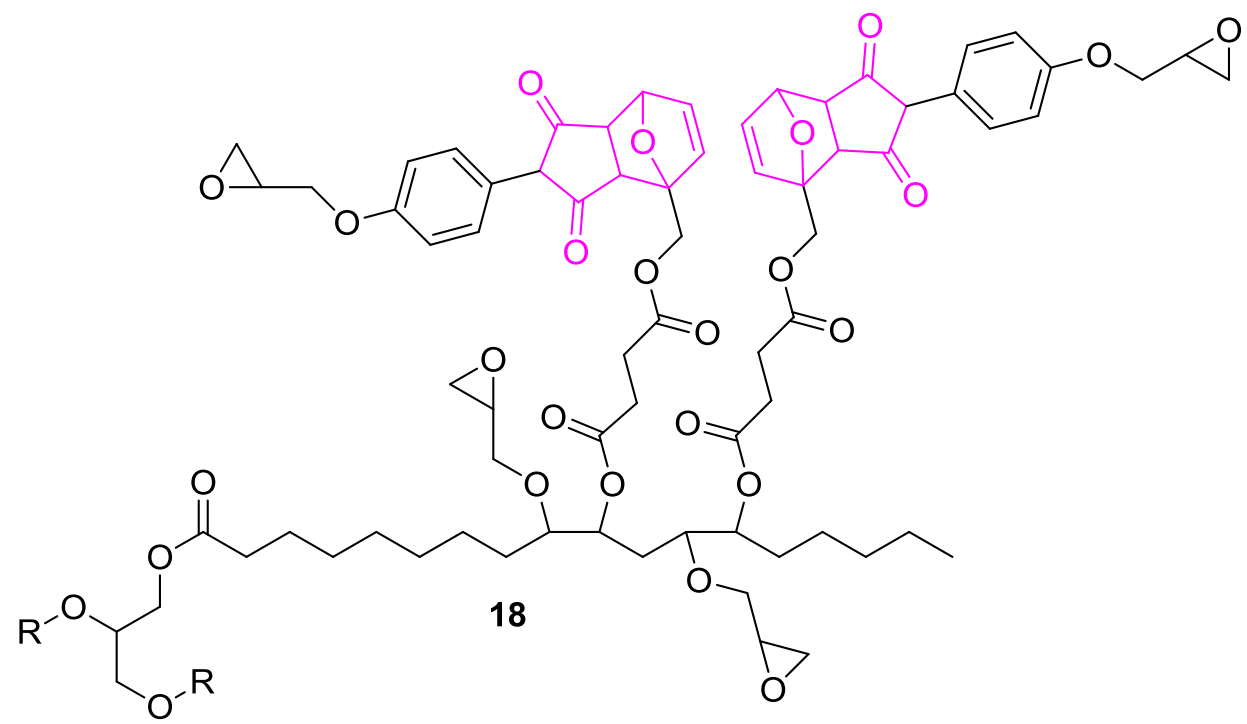

\subsection{Results and Discussion}

The synthesis of the compounds described in the previous section were met with various degrees of success for a number issues which will be discussed. The most promising synthetic pathways proved to be the synthesis of the various phenol terminated Diels-Alder linkage incorporated soy-bean oil compounds $(15,16$, and 17). 
3.3.1 Inconsistent molecular weight and high degree of reactivity of chlorosilanes

The synthesis of compounds $5, \mathbf{6}$, and $\mathbf{7}$ has proven to be more difficult than it would seem due to the high reactivity of chlorosilanes with water. This high degree of reactivity can lead to non-reactive polymer chains, as well as chain extension leading to inconsistencies in stoichiometric ratios of the synthetic Schemes. Figure 3.3.1 shows the reaction of the utilized chlorosilanes with water and the subsequent chain killing and extension.

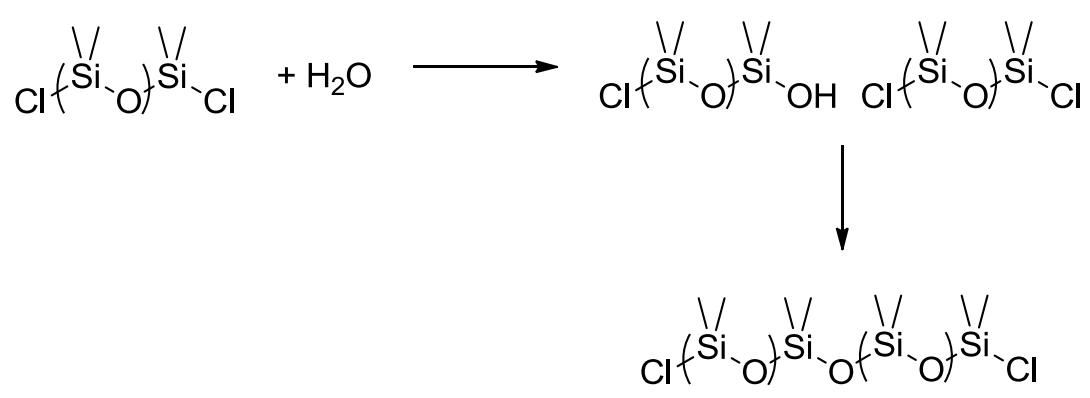

Figure 3.3.1. The conversion of chlorosilane terminated PDMS to silanol terminated PDMS by water followed by the subsequent reaction of silanol groups with chlorosilanes leading to chain extention.

3.3.2 Crystallinity, solubility and Michael addition of maleimide compounds In addition to quenching of the chlorosilane chain ends and the chain extension issues which hinder the synthesis of compounds 5,6 , and 7 , the produced silanol is able to undergo 1,4 Michael addition to the maleimide of compound $\mathbf{4}$, forming a permanent bond and eliminating the maleimides potential as a dienophile in reversible Diels-Alder linkages. The permanent addition of silanol to compound $\mathbf{4}$ is shown in Figure 3.3.2. 
cltsi. of ${ }^{\mathrm{Si}}{ }_{-\mathrm{OH}}$<smiles>O=C1C=CC(=O)N1c1ccc(O)cc1</smiles>

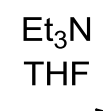<smiles>C[Si](C)(Cl)OC1CC(=O)N(c2ccc(O)cc2)C1=O</smiles>

Figure 3.3.2. The permanent Michael addition of silanol to maleimide.

The susceptibility of the maleimide group to Michael addition is also a significant hindrance in the synthesis of compound $\mathbf{8}$. The addition of amines to maleimides is well documented for many applications. ${ }^{12}$ During the synthesis, compound $\mathbf{3}$ is converted to an acid chloride, which also are designed to be highly reactive with amines. This creates a permanent crosslinker between Jeffamine polymers, creating an irreversibly crosslinked thermoset matrix, this outcome is shown in Figure 3.3.3. This permanent crosslinking effect can be overcome by reacting the Jeffamine with a vast excess of acid chloride modified compound $\mathbf{3}$, but this introduces more problems due to solubility issues of the aromatic maleimide compounds as described below.

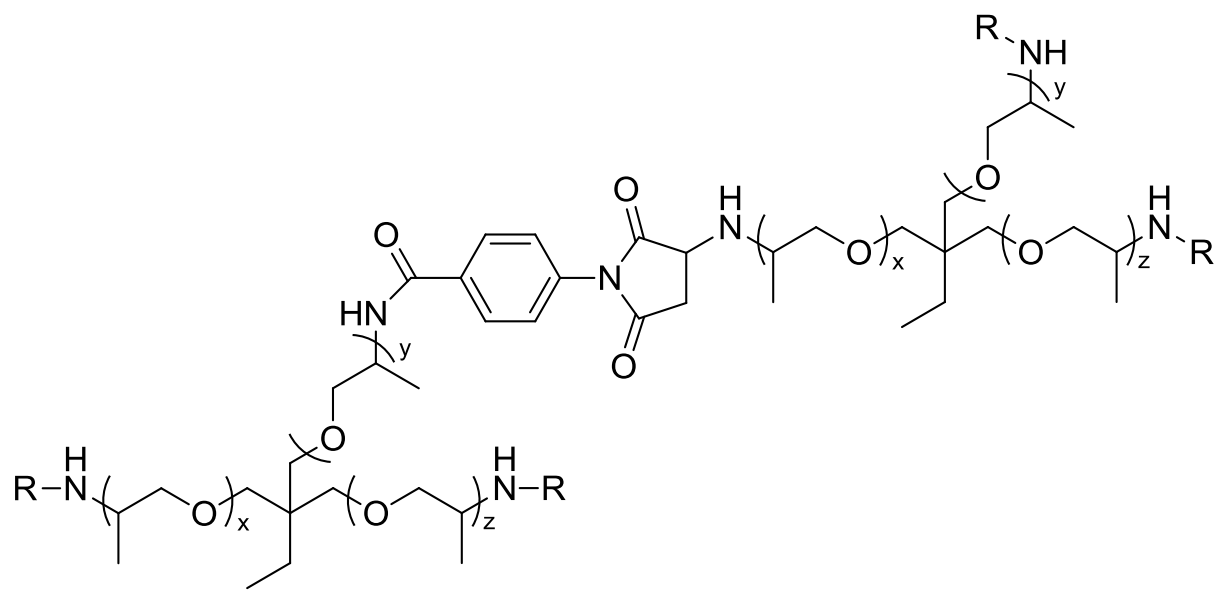

Figure 3.3.3. The permanent crosslinking of Jeffamine systems due to the Michael addition of amines to the maleimide. 
Observing the structure of compounds $\mathbf{3}$ and $\mathbf{4}$ hints at their crystallinity through both pi stacking of their aromatic regions and the hydrogen bonding of the carboxylic acid, phenol, and maleimide groups. In addition to contributing to crystallinity, the rival solubilities of the hydrophobic aromatic benzene core and hydrophilic exterior components of the molecules lead to solubility issues of these compounds which make performing many reactions difficult. These solubility issues show themselves in the synthesis of both compounds $\mathbf{5}$ and $\mathbf{8}$.

In the synthesis of compound $\mathbf{5}$, in addition to the complications mentioned previously, the addition of compound 4 to the PDMS made the polymer biphasic, existing in both liquid and crystalline states, in addition to complex solubility, the combination of these issues made the synthesis of compounds $\mathbf{6}$ and $\mathbf{7}$ difficult to achieve in high yields for additional testing.

The synthesis of compound $\mathbf{8}$ also was troubled by the solubility issues of compound 3. Initially, compound $\mathbf{3}$ must be converted into its acid chloride form, this reaction is done with oxalyl chloride in dichloromethane with a catalytic amount of DMF. Compound $\mathbf{3}$ however is very slightly soluble in dichloromethane and dissolves only as the reaction takes place, this causes the reaction to occur slowly. Once the acid chloride is formed, a vast excess of the compound is reacted with the Jeffamine polymer to yield compound $\mathbf{8}$, the molecular weight of which is more than $60 \%$ due to the compound 3 chain ends which had been added to the polymer. This leads to a highly crystalline polymer which has solubility properties similar to those of the excess compound $\mathbf{3}$ present in the product, leading to blend of compound $\mathbf{8}$ and compound $\mathbf{3}$ from which it is 
very difficult to isolate either product. Work on this product mixture is still underway and progress is steady. A suitable solvent system for the synthesis of compound $\mathbf{1 1}$ has yet to be determined and new systems are being evaluated for their potential.

3.3.3 Self epoxide opening in epoxidized soy-bean oil

During the synthesis of compound $\mathbf{1 4}$, as epoxides on the soy-bean oil are opened, the alcohols produced are able to then open epoxides present on other soy-bean oil molecules, polymerizing and crosslinking the oil. This reaction is aided by the presence of the carboxylic acid from compound $\mathbf{1}$, the product from this reaction is shown in Figure 3.3.4.

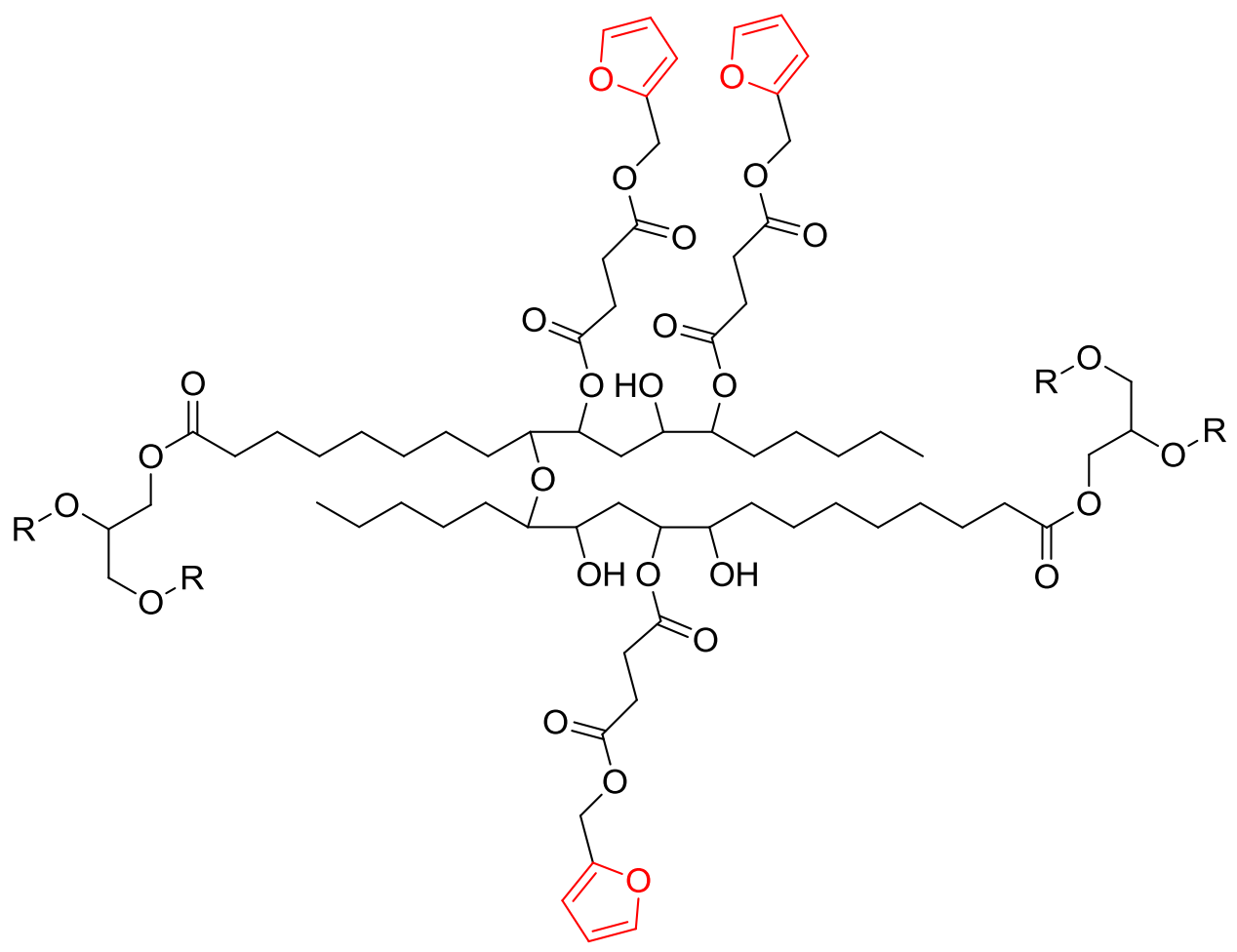

Figure 3.3.4. The self opening of soy-bean oil epoxide molecules. 
The self epoxide opening of the soy-bean oil can be overcome by employing the use of a vast excess of compound 1 during the synthesis. The carboxylic acids are more reactive and less stericly hindered than the alcohols which are formed along the fatty acid chain as a result of epoxide opening. Thus compound 14 can be synthesized and isolated in reasonable yields (90\%).

\subsubsection{Conclusions and future work}

The synthetic procedures of the formation of compounds 5,6 , and 7 must be improved to overcome the effects of water and Michael addition, discussed above, on the products. This is work which will be continued in this ongoing project.

While the synthetic procedure for the formation of compound $\mathbf{8}$ has been optimized, the isolation techniques employed must be refined to purify the desired polymer for further synthesis and ultimately crosslinking and testing. Alternate isolation techniques will continue to be explored until compound $\mathbf{8}$ can be isolated in its pure form.

The most successful synthetic routes accomplished in this study were the formations of the Diels-Alder modified soy-bean oil types. Both compounds 15 and 16 have been successfully synthesized at yields of $90 \%$ and $60 \%$ respectively. The resulting polymer was crosslinked using isophorene diisocyanate (IPDI). The synthesis of compound $\mathbf{1 7}$ is nearly complete. In order to test the effects of varying the amount of reversible and permanent crosslink sites in thermosets formed from the modified soy-bean oil with IPDI, changes in the amount of compound 4 used in the synthesis of compounds 15,16 , and 17 
will be made according to Table 3.1. The percentage of compound 4 used is based upon 4.4 alkenes per molecule of soy-bean oil, which is the calculated average based upon the composition of fatty acids in soy-bean oil. If the synthetic scheme uses $100 \%$ of compound 4 , it is assumed that all of the dienes present will be converted to reactive phenols, while using $50 \%$ of compound 4 will yield a material in which $50 \%$ of the dienes present are converted into reactive phenols, and $50 \%$ will be left as dienes which are inert in isocyanate crosslinking chemistry. The appropriate amount of IPDI is then used based upon the number of reactive phenols and alcohols in the modified soy-bean oil. Testing on the resulting reversibly crosslinked thermoset matrix will then be performed. Tests will include dynamic scanning calorimetry, dynamic mechanical analysis, and rheology. Further crosslinking and testing will be performed by the Costanzo research group.

Table 3.1. Reversible and permanent crosslink sites per molecule of modified soy-bean oil based on the percentage of compound 4 reacted with a baseline $100 \%$ of diene available for reaction.

\begin{tabular}{ccccc}
\hline & & & \multicolumn{2}{c}{ \# of crosslink sites per molecule } \\
\cline { 4 - 5 } Sample & compound & \% Diels-Alder & permanent & reversible \\
\hline 1 & $\mathbf{1 5}$ & 100 & 4.4 & 4.4 \\
2 & $\mathbf{1 5}$ & 50 & 4.4 & 2.2 \\
3 & $\mathbf{1 6}$ & 100 & 0 & 4.4 \\
4 & $\mathbf{1 6}$ & 50 & 0 & 2.2 \\
5 & $\mathbf{1 7}$ & 100 & 0 & 8.8 \\
6 & $\mathbf{1 7}$ & 50 & 0 & 4.4 \\
7 & $\mathbf{1 7}$ & 25 & 0 & 2.2 \\
\hline
\end{tabular}


Once satisfactory testing of the reversibly crosslinkable matrix formed from the Diels-Alder modified soy-bean oil is completed, the nanoparticle component will be introduced into the matrix. Silica nanoparticles of various diameters will be introduced as bare nanoparticles, nanoparticles with permanently tethered polymer brush surfaces, and nanoparticles with reversibly tethered polymer brush surfaces. Schemes will also be employed which utilize the nanoparticle themselves as a crosslinking agent in both a permanent and reversible fashion. 


\subsection{Experimental Techniques}

\subsubsection{Materials}

All starting materials were purchased from commercially available sources and used without any further purification.

\subsubsection{Instrumental}

${ }^{1} \mathrm{H}$ and ${ }^{13} \mathrm{C}$ NMR spectroscopy was conducted on either a $300 \mathrm{MHz}$ Bruker spectrometer in d-acetone, d-DMSO, or $\mathrm{CDCl}_{3}$, chemical shifts are reported as $\delta(\mathrm{ppm})$, referenced to the residual solvent peak.

\subsubsection{Synthetic techniques}

\subsubsection{Synthesis of Carboxy-ester-furan (1)}

To a $500 \mathrm{~mL}$ round bottom flask equipped with a magnetic stir bar was added succinic anhydride $(5.000 \mathrm{~g}, 49.97 \mathrm{mmol})$ followed by a catalytic amount of dimethylaminopyridine (DMAP) $(0.300 \mathrm{~g})$. Toluene $(115 \mathrm{~mL})$ was then added and the solution was refluxed at $120^{\circ} \mathrm{C}$ until the succinc anhydride and DMAP melted. Furfuryl alcohol $(4.902 \mathrm{~g}, 49.97 \mathrm{mmol})$ was then added and the solution was allowed to stir under reflux for $24 \mathrm{~h}$ The toluene was then evaporated under vacuum leaving a dark residue which was dissolved in diethyl ether $(100 \mathrm{~mL})$ and washed with $\mathrm{HCl}(2.5 \%, 100 \mathrm{~mL}, 1 \mathrm{X})$. The ether layer was collected and dried with magnesium sulfate, filtered and evaporated under vacuum yielding a dark liquid product ( $8.955 \mathrm{~g}, 90 \%$ yield) which was confirmed by ${ }^{1} \mathrm{HNMR}: \delta$ (ppm) 7.45 $(1 \mathrm{H}, \mathrm{s}), 6.4(1 \mathrm{H}, \mathrm{d}), 6.35(1 \mathrm{H}, \mathrm{t}), 5.5(2 \mathrm{H}, \mathrm{s}), 2.15(4 \mathrm{H}, \mathrm{m})$. 


\subsubsection{Synthesis of Boc-furfurylamine (2)}

To a $100 \mathrm{~mL}$ round bottom flask equipped with a magnetic stir bar was added furfuryl amine $(1.116 \mathrm{~g}, 11.50 \mathrm{mmol})$ followed by of dichloromethane (40 $\mathrm{mL})$ and triethylamine $(2.326 \mathrm{~g}, 22.99 \mathrm{mmol})$. Di-tert-butyl dicarbonate $(3.763 \mathrm{~g}$, $17.243 \mathrm{mmol}$ ) was then added and the solution was stirred at room temperature for $4 \mathrm{~h}$ The reaction mixture was then washed with brine $(40 \mathrm{~mL}, 3 \mathrm{X})$. The dichloromethane layer was collected and dried with magnesium sulfate, filtered and evaporated under vacuum. The product was recovered (quantitative yield) and structure was then confirmed using ${ }^{1} \mathrm{HNMR}$ : $\delta(\mathrm{ppm}) 7.3(1 \mathrm{H}, \mathrm{d}), 6.27(1 \mathrm{H}$, m), $6.17(1 \mathrm{H}, \mathrm{d}), 5.25(2 \mathrm{H}, \mathrm{s}), 1.41(9 \mathrm{H}, \mathrm{s})$.

\subsubsection{Synthesis of Carboxy-maleimide (3)}

A $500 \mathrm{~mL}$ Erlenmeyer flask equipped with a magnetic stirbar was loaded with maleic anhydride $(10 \mathrm{~g}, 102 \mathrm{mmol})$ and acetone $(150 \mathrm{~mL})$. The mixture was stirred until dissolved to which 4-aminobenzoic acid (13.98 g, $102 \mathrm{mmol})$ was slowly added. The mixture was stirred at room temperature for 2 hours during which a yellow precipitate was formed. The precipitate was collected via vacuum filtration, washed with acetone, dried and transferred to a $200 \mathrm{~mL}$ round bottom flask equipped with a magnetic stirbar. Potassium carbonate $(500 \mathrm{mg}, 3.6 \mathrm{mmol}$ ) was added to the flask followed by acetic anhydride $(19.3 \mathrm{~mL}, 204 \mathrm{mmol})$ in dimethylformamide (DMF) $(75 \mathrm{~mL})$. The reaction mixture was stirred at $80^{\circ} \mathrm{C}$ for 2 hours and then allowed to come to room temperature. Subsequently the mixture was poured into an excess of ice water to obtain a pale yellow precipitate that was collected via vacuum filtration and recrystallized in 50/50 acetone/ethyl 
acetate to yield fine white crystals. $19.9 \mathrm{~g}$ yield $(90 \%) .{ }^{1} \mathrm{H}$ NMR: $\delta(p p m) 8.11$ $(2 \mathrm{H}, \mathrm{d}), 7.62(2 \mathrm{H}, \mathrm{d}), 7.03(2 \mathrm{H}, \mathrm{s})$.

3.4.3.4 Synthesis of Phenolic-maleimide (4)

To a $1000 \mathrm{~mL}$ Erlenmeyer flask equipped with a magnetic stir bar was added 4-aminophenol acid $(44.5 \mathrm{~g}, 400 \mathrm{mmol})$ followed by acetone $(500 \mathrm{~mL})$ and the mixture was stirred at room temperature. In a $500 \mathrm{~mL}$ beaker, maleic anhydride (40 g, $400 \mathrm{mmol})$ was dissolved in acetone $(300 \mathrm{~mL})$, this mixture was then added to the Erlenmeyer flask slowly and a yellow precipitate formed which was isolated by vacuum filtration. The product was added to a $300 \mathrm{~mL}$ round bottom flask equipped with a magnetic stir bar followed by DMF $(50 \mathrm{~mL})$. To a $150 \mathrm{~mL}$ beaker equipped with a stir bar was added DMF ( $70 \mathrm{~mL})$, followed by ( 21 $\mathrm{g}, 140 \mathrm{mmol}$ ) and fuming sulfuric acid $(9 \mathrm{~g}, 91.8 \mathrm{mmol}$ ) (weighed out in a $10 \mathrm{~mL}$ graduated cylinder), and additional DMF (20 mL) which was used to rinse the sulfuric acid from the graduated cylinder into the beaker; this mixture was then added to the $300 \mathrm{~mL}$ round bottom flask which was sealed with a rubber septa and allowed to stir at $70^{\circ} \mathrm{C}$ for $24 \mathrm{~h}$ The resulting viscous black liquid was then poured into a $4 \mathrm{~L}$ beaker containing ice water $(3 \mathrm{~L})$, precipitating a fine yellow powder which was isolated by vacuum filtration and recrystalized in isopropanol ( $40 \mathrm{~g}$ crude product $/ 310 \mathrm{~mL}$ isopropanol). The structure of the resulting yellow crystals (55 g, 65\% yield) was then confirmed via ${ }^{1} \mathrm{HNMR}: \delta(p p m) 7.15(2 \mathrm{H}, \mathrm{d})$, $7.0(2 \mathrm{H}, \mathrm{s}), 6.9(2 \mathrm{H}, \mathrm{d})$. 


\subsubsection{Synthesis of Maleimide-PDMS (5)}

To a $200 \mathrm{~mL}$ round bottom flask equipped with a stir bar was added compound 4 (2.384 g $12.62 \mathrm{mmol})$, followed by THF $(60 \mathrm{~mL})$ and triethylamine $(1.336 \mathrm{~g}, 13.24 \mathrm{mmol})$. This solution was stirred at $0^{\circ} \mathrm{C}$ for 10 minutes then to it was added dichlorosilane terminated polydimethylsiloxane $(12.00 \mathrm{~g}, 1000-3000$ $\mathrm{g} / \mathrm{mol}$ giving approximately $6 \mathrm{mmol}$ ). The solution was then allowed to stir at room temperature for $4 \mathrm{~h}$ after which the THF was evaporated under vacuum yielding a bright yellow oil with yellow solids which were separated by vacuum filtration. ${ }^{1} \mathrm{HNMR}$ of both components gave inconsistent ratios of maleimide peaks from compound $\mathbf{4}$ to PDMS backbone peaks, because of this discrepancy this synthetic technique is being refined.

\subsubsection{Synthesis of Boc-amine-DA-PDMS (6)}

In a $25 \mathrm{~mL}$ round bottom flask, compound $5(1.162 \mathrm{~g}, 0.414 \mathrm{mmol})$ was added followed by THF (10 mL) and compound $2(0.1634 \mathrm{~g}, 0.828 \mathrm{mmol})$. The solution was left to sit for $48 \mathrm{~h}$ at room temperature followed by the evaporation of the THF under vacuum leaving a yellow oil. ${ }^{1} \mathrm{HNMR}$ of the product showed that there was still excess maleimide in the product so the product was redisolved in THF and titrated with compound 2 until ${ }^{1} \mathrm{HNMR}$ confirmed the maleimide peak to be gone (showing the completion of the Diels-Alder reaction).

\subsubsection{Synthesis of amine-DA-PDMS (7)}

To a $50 \mathrm{~mL}$ round bottom flask equipped with a magnetic stir bar compound 6 was added followed by a 50 / 50 dichloromethane / trifuoroacetic acid solution $(20 \mathrm{~mL})$. This solution was stirred at room temperature for $4 \mathrm{~h}$ 
followed by the evaporation of the deprotecting solution under vacuum to yield a yellow oil product. ${ }^{1} \mathrm{HNMR}$ of the product showed an unacceptable decomposition of the polymer so other deprotection techniques are being explored.

\subsubsection{Synthesis of Maleimide-Jeffamine T-403 (8)}

To a $100 \mathrm{~mL}$ round bottom flask equipped with a magnetic stir bar was added compound $3(4.000 \mathrm{~g}, 18.42 \mathrm{mmol})$ followed by dichloromethane $(15 \mathrm{~mL})$, this solution was then stirred at room temperature. To a $50 \mathrm{~mL}$ Erlenmeyer flask was added dichloromethane $(15 \mathrm{~mL})$ followed by oxalyl chloride $(3.507 \mathrm{~g}, 27.63$ $\mathrm{mmol}$ ), this solution was added slowly to the compound $\mathbf{3}$ solution, followed by catalytic DMF (5 drops). A desiccating column of Drierite was attached to the flask to allow for the release of gases produced by the reaction. The reaction was left to stir at room temperature for $4 \mathrm{~h}$ after which toluene $(15 \mathrm{~mL})$ was added to the solution and then all excess liquids were evaporated under vacuum leaving a bright yellow, granular solid. This product was dissolved in anhydrous THF (15 mL) and added dropwise to a $100 \mathrm{~mL}$ round bottom flask equipped with a magnetic stir bar which already contained Jeffamine T-403 (2.316 g, 5.26 $\mathrm{mmol})$ and triethylamine $(1.704 \mathrm{~g}, 16.84 \mathrm{mmol})$ dissolved in anhydrous THF(20 $\mathrm{mL}$ ). The reaction was allowed to stir at room temperature for $4 \mathrm{hrs}$ and the THF was then evaporated under vacuum yielding a bright red, transparent, cryastalline solid. ${ }^{1}$ HNMR confirmed that the addition of the acid chloride modified compound $\mathbf{3}$ had occurred at the desired location by the disapearence of primary amine hydrogen signals and the appearance of an amide hydrogen 
signal, however it was also evident that excess compound $\mathbf{3}$ was also present and due to solubility issues described above the isolation of the polymer has been unsuccessful and new isolation techniques are being explored.

3.4.3.9 Synthesis of epoxidized soybean oil (13)

To a $250 \mathrm{~mL}$ Erlenmeyer flask equipped with a stir bar was added soybean oil ( $50.0 \mathrm{~g}, 54.7 \mathrm{mmol})$ followed by formic acid $(16.65 \mathrm{~g}, 361.7 \mathrm{mmol})$ and the mixture was stirred on ice for ten minutes. Hydrogen peroxide solution $(30 \%$, $65.45 \mathrm{~g}$ ) was then slowly added to the flask which was then allowed to stir at room temperature for $48 \mathrm{~h}$ Diethylether $(100 \mathrm{~mL})$ was then added to the flask to dissolve the oil and separate it from the aqueous peroxide/acid solution, which was removed and discarded and the ether layer was transferred to a $500 \mathrm{~mL}$ Erlenmeyer flask. Saturated sodium bicarbonate solution (50 mL increments) was then carefully added to the ether solution until gentle shaking of the mixture ceased to produce gas. The aqueous layer was then separated and discarded and the ether solution was washed with D.I. water $(50 \mathrm{~mL})$. The ether solution was then dried over magnesium sulfate and the ether was evaporated under vacuum yielding a clear, very slightly yellow colored oil (48 g, 88\% yield). ${ }^{1} \mathrm{HNMR}$ confirmed the epoxidation by the appearance of epoxide peaks at $\delta$ (ppm) 2.85, 2.95 and 3.1 and the disappearance of alkene peaks at $\delta(p p m) 5.3$.

\subsubsection{Synthesis of diene soybean oil (14)}

To a $25 \mathrm{~mL}$ round bottom flask equipped with a magnetic stir bar was added compound 13 (2.704 g, $2.76 \mathrm{mmol}$ ) followed by compound 1 (4.374 g, $22.0 \mathrm{mmol}$ ). The mixture was then stirred at $110^{\circ} \mathrm{C}$ for $24 \mathrm{~h}$ after which it was 
dissolved in ether $(30 \mathrm{~mL})$ and washed with $\mathrm{NaOH}$ solution $(5 \%, 30 \mathrm{~mL}, 1 \mathrm{X})$. The ether layer was collected and dried over magnesium sulfate and the ether was evaporated under vacuum yielding a dark colored viscous oil (quantitative yield). ${ }^{1} \mathrm{HNMR}$ confirmed the structure of the product by the disapearence of the epoxide peaks at $\delta$ (ppm) 2.85, 2.95 and 3.1 and the appearance of furan peaks at $\delta(\mathrm{ppm}) 6.35,6.4$ and 7.4 in the proper ratio.

3.4.3.11 Synthesis of phenol-DA-soybean oil (15)

In a $25 \mathrm{~mL}$ round bottom compound $14(3.683 \mathrm{~g}, 2.078 \mathrm{mmol})$ was dissolved in THF (15 mL) followed by the addition of compound $4(1.730 \mathrm{~g}, 9.143$ $\mathrm{mmol}$ ). The solution was then allowed to sit at room temperature for $48 \mathrm{~h}$ The THF was then evaporated under vacuum, leaving a dark oil (quantitative yield). ${ }^{1} \mathrm{HNMR}$ confirmed the formation of compound 15 by the disapearence of the furan peaks at $\delta p p m 6.35,6.4$ and 7.4 and the appearance of the appropriate Diels-Alder adduct peaks: $\delta$ (ppm) 6.55, 6.4, 5.35, 3.05 and 2.95 .

3.4.3.12 Synthesis of acetylated phenol-DA-soybean oil (16)

To a $100 \mathrm{~mL}$ round bottom flask equipped with a magnetic stir bar was added compound 14 (3.00 g, $1.69 \mathrm{mmol})$ followed by THF (40 mL) and triethylamine $(0.7415 \mathrm{~g}, 7.277 \mathrm{mmol})$ and acetic anhydride $(0.7084 \mathrm{~g}, 6.939$ $\mathrm{mmol}$ ). The reaction was then stirred under reflux for $24 \mathrm{~h}$ followed by the evaporation of the THF under vacuum. The product was redissolved in ether (40 $\mathrm{mL}$ ) and washed with brine (40 mL, 1X). The ether layer was collected, dried over magnesium sulfate, filtered and evaporated under vacuum to yield a dark viscous oil (quantitative yield). This product was then dissolved in THF (40 mL) 
and it was reacted with compound $\mathbf{1}$ in a similar fashion to that of the synthesis of compound 15, yielding a dark oil (quantitative yield). ${ }^{1} \mathrm{HNMR}$ confirmed the formation of the Diels-Alder adduct as was described for compound 15, however in addition there was a new peak at $\delta(\mathrm{ppm}) 2.05$ corresponding to the acetylation of the alcohols along the fatty acids. 


\subsection{References}

(1) Khosh, R. L.; Bagheri, R.; Zokaei, S. Journal of Applied Polymer Science 2008, 110, 4040.

(2) Yao, X. F.; Zhou, D.; Yeh, H. Y. Aerospace Science and Technology 2008, 12, 223.

(3) Zhang, H.; Tang, L.-C.; Zhang, Z.; Friedrich, K.; Sprenger, S. Polymer 2008, 49, 3816.

(4) Zhao, S.; Schadler, L. S.; Duncan, R.; Hillborg, H.; Auletta, T. Composites Science and Technology 2008, 68, 2965.

(5) Lee, J.-Y.; Zhang, Q.; Emrick, T.; Crosby, A. J. Macromolecules 2006, 39, 7392.

(6) Costanzo, P. J.; Demaree, J. D.; Beyer, F. L. Langmuir 2006, 22, 10251.

(7) Poovarodom, S.; Hosseinpour, D.; Berg, J. C. Industrial \& Engineering Chemistry Research 2008, 47, 2623.

(8) Lee, J.-Y.; Zhang, Q.; Wang, J.-Y.; Emrick, T.; Crosby, A. J. Macromolecules 2007, 40, 6406.

(9) Swanson, J. P.; Rozvadovsky, S.; Seppala, J. E.; Mackay, M. E.; Jensen, R. E.; Costanzo, P. J. Macromolecules 2010, 43, 6135.

(10) Costanzo, P. J.; Beyer, F. L. Chemistry of Materials 2007, 19, 6168.

(11) Yang, L.; Dai, H.; Yi, A.; Lin, B.; Li, G. Journal of Thermal Analysis and Calorimetry 2008, 93, 875.

(12) Okumoto, S.; Yamabe, S. The Journal of Organic Chemistry 2000, 65, 1544. 


\section{Conclusions and Future Applications}

4.1 The future of composites and nanocomposites

The field of nanocomposite technology is growing at an estimated annual rate of $25 \%$. This growth branches into a wide array of applications including improvement in gas barrier properties for oxygen and water vapor; the development of materials with novel magnetic, electronic, and optical properties; and adding incredible amounts of strength and toughness to ultra-light weight materials. Such materials will carry mankind into the future, but focus on these futuristic materials cannot draw attention away from current problems facing society, including the monetary and human costs of corrosion.

While the problems brought about by corrosion and the application of new polymeric materials to mediate them may not be as glamorous as developing so called "space age" materials, they still require the same attention. The $\$ 2.2$ trillion spent on corrosion annually worldwide can be decreased by changing the materials which are used in the construction or the protection of the world's infrastructure. More importantly, the retrofitting of current aging infrastructure with composite materials to add strength and corrosion protection can prevent disastrous infrastructure failures possibly saving lives.

4.2 Control of surface energy and wettability via Diels-Alder chemistry

Diels-Alder chemistry was successfully employed in providing a reversible linkage for controlling the surface energy and wettability of glass substrates.

Dienes were attached to the glass slides providing a wetting surface which was confirmed using contact angle (CA) measurements, this diene functionalized 
surface gave CA $-70 \pm 3^{\circ}$. Hydrophobic dienophiles which were prepared using fluorinated alkyl chains, when reacted with the dienes on the surface, the surface energy was significantly changed $\left(\mathrm{CA}-101 \pm 9^{\circ}\right)$. Cleavage of the hydrophobic chains from the surface by using heat to trigger the retro Diels-Alder reaction, this returned the surface energy back to its previous state $\left(C A-70 \pm 6^{\circ}\right)$. The treatments were then applied to glass capillaries, the differences in surface energy were confirmed using fluid column measurements, fluid was unable to penetrate into the hydrophobic capillary under testing conditions, again signifying significant surface energy difference. Patterned capillary tubes were then functionalized in order to create a transition zone of higher and lower surface energy. The interface within the capillary was shown to act as an effective fluid flow gate based only upon the surface energy of the walls of the capillary. Experiments were attempted to create capillaries which could self expunge fluid, these attempts proved to be unsuccessful due to hysteresis of the hydrophobic surface. The ability to create fluid flow gates in capillary systems provides a means by which a controlled vascular system can be incorporated into composite materials.

\subsection{Responsive matrix and nanofillers via Diels-Alder chemistry}

The incorporation of Diels-Alder linkages into various polymeric thermoset binder systems was met with varying degrees of success. The most promising synthetic technique employed epoxidized soybean oil which was modified by placing dienes along the fatty acid chains of the oil molecules, which also produced alcohol groups along the chains. The alcohols produced can either be 
left as is, allowing them to form permanent linkages in subsequent crosslinking reactions, they can be acetylated, rendering them inert in subsequent crosslinking chemistry, or they can be further functionalized with additional dienes. Once the alcohols are functionalized as desired, the dienes are reacted with dienophiles which are functionalized with reactive phenol groups. The reactive phenol groups which present along the fatty acid chains are linked by a reversible Diels-Alder linkage, the phenol groups are then available for crosslinking with isocyanate prepolymers to yield a reversibly crosslinked thermoset matrix. Such a matrix can potentially enhance the increased fracture toughness imparted on thermoset nanocomposites by increasing the mobility of nanofillers. 


\title{
Langmuir
}

pubs.acs.org/Langmuir

(C) 2009 American Chemical Society

\section{Controlling Surface Energy and Wetability with Diels-Alder Chemistry}

\author{
Philip T. Dirlam,${ }^{\dagger}$ Gregory A. Strange,${ }^{\dagger}$ Joshua A. Orlicki, $^{*}$ Eric D. Wetzel,${ }^{\star}$ and \\ Philip J. Costanzo*, \\ ${ }^{\dagger}$ Department of Chemistry and Biochemistry, California Polytechnic State University, San Luis Obispo, \\ California 93407-0402 and *Army Research Laboratory, Materials Division, Aberdeen Proving Ground, \\ Aberdeen, Maryland 21005-5069
}

Received September 1, 2009. Revised Manuscript Received November 10, 2009

\begin{abstract}
Reversible Diels-Alder chemistry was utilized to manipulate the surface energy of glass substrates. Hydrophobic dieneophiles were prepared and attached to glass slides and capillaries to yield a nonwetting surface. Thermal treatment of the surfaces cleaved the Diels-Alder linkage, and resulted in the fabrication of a hydrophilic surface. Preliminary analysis utilized contact angle (CA) measurements to monitor the change in surface energy, and observed a hydrophilic state $\left(\mathrm{CA}-70 \pm 3^{\circ}\right)$ before attachment of the dieneophile to a hydrophobic state $\left(\mathrm{CA}-101 \pm 9^{\circ}\right)$ followed by regeneration of the hydrophilic state $\left(\mathrm{CA}-70 \pm 6^{\circ}\right)$ upon cleavage of the Diels-Alder linkage. The treatments were then applied to glass capillaries, with effective treatment confirmed by fluid column measurements. Patterned treatments were also demonstrated to provide effective flow gating. Finally, attempts to create self-pressurizing capillaries were unsuccessful due to pronounced contact angle hysteresis for the hydrophobic surface treatment.
\end{abstract}

\section{Introduction}

A number of researchers have recently demonstrated the ability to create vascularized structures, using techniques such as hollow glass capillaries ${ }^{1-3}$ and direct-write fugitive inks. ${ }^{4,5}$ These vascularized systems could impart many new functionalities to structural materials, such as active thermal management, self-healing, and mechanical property adaptation. In a related field, rapid progress in microfluidic devices has led to important new capabilities in a range applications, including forensics, genomics, pharmaceuticals, healthcare, and biodetection. ${ }^{6,7}$

All of these applications require fluid flow in small channels. The driving force for this flow is typically provided by an external mechanical pump coupled to the flow system. However, for some applications, the weight, volume, complexity, and power requirements of conventional pumps are not acceptable, and techniques for developing internal pressurization without external devices are desired. Examples of such novel stand-alone systems would include a self-healing structural component in an aircraft or a compact, low-cost biodetection device for remote military applications. Similarly, active control of internal flow characteristics such as path and velocity is typically executed via miniature valves and gates, which introduce system complexity while reducing robustness.

A less-burdensome alternative to mechanical pumps, valves, and gates is to control flow via surface effects. A channel wall that can be switched from wettable to nonwettable relative to the vascular fluid can be used to induce surface tension-driven pressurization of the flow. Patterning wettable and nonwettable surfaces enables controlled pressure drops, gated flow regions,

*Corresponding author. E-mail address: pcostanz@calpoly.edu.

(1) Trask, R. S.; Bond, I. P. Smart Mater. Struct. 2002, 15, 704-710.

(2) Trask, R. S.; Bond, I. P.; Williams, G. J. J. R. Soc. Interface 2006, 4, 363-371.

(3) Bond, I. P.; Pang, J. W. C. Composites 2005, 36, 183-188.

(4) Therriault, D.; White, S. R.; Lewis, J. A. Nat. Mater. 2003, 2, 265-271.

(5) Therriault, D.; White, S. R.; Lewis, J. A.; Shepher, R. F. Adv. Mater. 2005, 17, 395-399.

(6) Franke, T. A.; Wixforth, A. ChemPhysChem 2008, 9, 2140-2156.

(7) Whitesides, G. M. Nature 2006, 442, 368-373. and control of flow pathways. These approaches are analogous to the strategies used by plants to control vascular flow ${ }^{8}$ and can be contrasted to the utilization of a heart (a centralized pump) in animals.

The concept of tailoring internal surface chemistry to control channel flows has been demonstrated previously. Liang et al. demonstrated a thermally active glass capillary coating whose contact angle could be tailored from strongly hydrophilic to weakly hydrophilic by varying the temperature over a $30{ }^{\circ} \mathrm{C}$ temperature range. ${ }^{9}$ Suk and Cho showed that patterning hydrophobic and hydrophilic surfaces could be used to tailor microflow characteristics. ${ }^{10}$ Caprioli et al. demonstrated a photoactive capillary coating through which contact angle could be varied by up to $20^{\circ}$ via ultraviolet illumination. ${ }^{11}$

In the present study, Diels-Alder chemistries are combined with a range of functional groups to develop and demonstrate tailorable surfaces. In a traditional Diels-Alder reaction, a diene is attacked by a dieneophile resulting in a ring structure. ${ }^{12,13}$ (Figure 1) Ring formation is temperature dependent and reversible by controlling the heating and cooling of the system. Incorporating these reversible bonds on a surface should allow for the control of functional surface chemistries and could lead to surfaces exhibiting invertible surface energies. This technique has been applied to a variety of materials including the preparation of organic-inorganic polymer hybrids, ${ }^{14-17}$ thermoplastic

(8) Wheeler, T. D.; Stroock, A. D. Nature 2008, 455, 208-212.

(9) Liang, L.; Feng, X.; Liu, J.; Rieke, P. C.; Fryxell, G. E. Macromolecules 1998 $31,7845-7850$.

(10) Suk, J.; Cho, J. J. Micromech. Microeng. 2007, 17, N11-N15.

(11) Caprioli, L.; Mele, E.; Angile, F. E.; Girardo, S.; Athanassiou, A.; Camposeo, A.; Cingolani, R.; Pisignano, D. App. Phys. Lett. 2007, 91, 110-113.

(12) Carruthers, W. Cycloaddition Reactions in Organic Synthesis; Oxford: Oxford, U.K., 1990

(13) Fringuelli, F.; Taticchi, A. Dienes in the Diels-Alder Reaction; John Wiley \& Sons: New York, 1990.

(14) Costanzo, P. J.; Demaree, J. D.; Beyer, F. L. Langmuir 2006, 22, 1025110257.

(15) Costanzo, P. J.; Beyer, F. L. Macromolecules 2007, 40, 3996-4001.

(16) Costanzo, P. J.; Beyer, F. L. Chem. Mater. 2007, 19, 6168-6173.

(17) Imai, Y.; Itoh, H.; Naka, K.; Chujo, Y. Macromolecules 2000, 33, 4343-4346. 
Scheme 1. Synthetic Route for Preparation of Diels-Alder Functionalized Glass Slides ${ }^{a}$

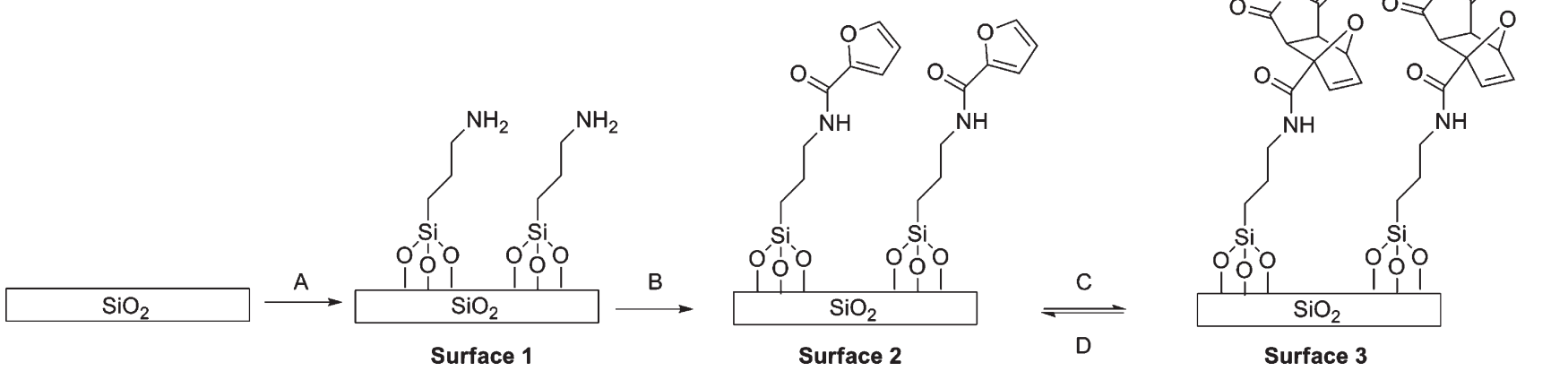

${ }^{a}$ Conditions: (A) 3-aminopropyltrimethoxysilane; (B) 2-furoyl chloride, $\mathrm{Et}_{3} \mathrm{~N}$, THF, $0{ }^{\circ} \mathrm{C}$ to room temperature, $24 \mathrm{~h}$; (C) compound 4, THF, room temperature, $24 \mathrm{~h}$; (D) toluene, reflux, $24 \mathrm{~h}$.

Scheme 2. Synthetic Route for Preparation of Fluorinated Maleimide ${ }^{a}$

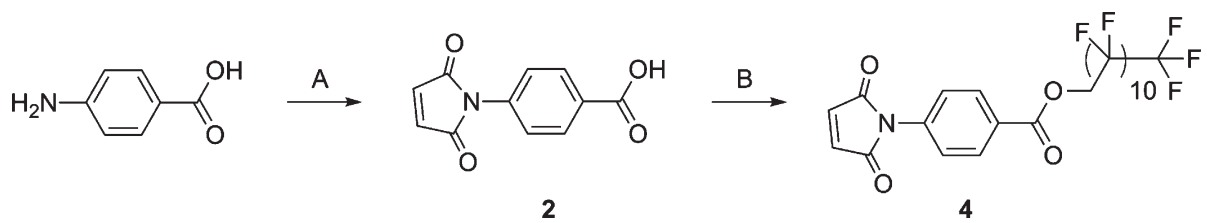

${ }^{a}$ Conditions: (A) maleic anhydride, acetic anhydride, $\mathrm{K}_{2} \mathrm{CO}_{3}$, DMF, $70{ }^{\circ} \mathrm{C}, 4 \mathrm{~h}$; (B) DIC, $1 \mathrm{H}, 1 \mathrm{H}$-perfluoro-1-dodecanol, DMAP, THF, $55^{\circ} \mathrm{C}, 24 \mathrm{~h}$.

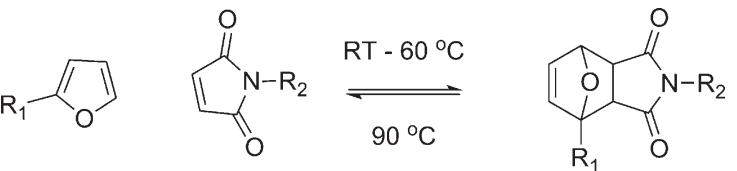

Figure 1. Reversible Diels-Alder adduct whose formation is temperature dependent.

elastomers, ${ }^{18,19}$ polyurethanes, and foams. ${ }^{20}$ By incorporating these reversible bonds into functional surface chemistries, we demonstrate the ability to create tailorable surfaces that can be transitioned between hydrophobic and hydrophilic states. Initial screening studies characterized the surface characteristics of coatings on flat glass substrates. The best methodology was then applied to glass capillaries where the wetability and capillary fill properties were investigated.

\section{Results and Discussion}

Scheme 1 illustrates the synthetic methodology for the incorporation of Diels-Alder linkages upon glass surfaces. Glass slides were first silanized with 3-aminopropyltrimethoxysilane (APS) to yield amino-terminated surfaces (surface 1). Amidation was then completed with 2-furfuryl chloride to prepare furan terminated surfaces (surface 2), which upon introduction of compound 2 , underwent a Diels-Alder reaction to yield a hydrophobic surface (surface 3). Compound $\mathbf{4}$ was prepared in a straightforward

(18) Gheneim, R.; Perez-Berumen, C.; Gandini, A. Macromolecules 2002, 35 , 7246-7253.

(19) Chen, X.; Wudl, F.; Mak, A. K.; Shen, H.; Nutt, S. R. Macromolecules 2003, 36, 1802-1807.

(20) Mcelhanon, J. R.; Russick, E. M.; Wheeler, D. R.; Low, D. A.; Aubert, J. H. J. Appl. Polym. Sci. 2002, 85, 1496-1502. manner by preparing 4-carboxylate maleimide followed by carbodiimide coupling with $1 \mathrm{H}, 1 \mathrm{H}$-perfluoro-1-dodecanol. (Scheme 2) XPS analysis was utilized to confirm surface functionalization. Figure 2 displays a large emission corresponding to the presence of fluorine indicating that the Diels-Alder reaction was successful. Contact angle measurements were utilized to monitor the change in surface functionality and energy. As displayed in Table 1, untreated glass slides were extremely hydrophilic (ca. $\sim 23 \pm 3^{\circ}$ ). Silanization of the slides was effective as the contact angle displayed a significant hydrophobic shift due to the incorporation of an organic alkyl chain while maintaining a narrow standard deviation (ca. $\sim 58 \pm 3^{\circ}$ ). A similar hydrophobic shift was observed upon addition of the furan to the substrate (ca. $\sim 70$ $\pm 3^{\circ}$ ). After completion of the Diels-Alder reaction with compound $\mathbf{4}$ a substantial change in contact angle was observed as the surface became fully hydrophobic $\left(\mathrm{CA} \sim 101 \pm 9^{\circ}\right)$. The fluorinated alkyl chain reduced the surface energy which increased the contact angle, although a larger standard deviation was observed. The scatter in the data was most likely caused by surface heterogeneity caused by the formation of crystalline domains, as it is well established that perfluorinated alkyl chains greater than eight carbons in length will crystallize. ${ }^{21}$ To probe this assertion, a six carbon fluorinated alkyl chain was employed to prepare a short-chain analogue (compound 3) that would be unable to crystallize due to the shorter chain length. In this sample, the contact angle was $65 \pm 2^{\circ}$, which was lower than the initial furan surface. It is hypothesized that the Diels-Alder linkage adopted a conformation in which the hydrophobic tail was intercalated within the organic layer which exposed either the amide or ester linkages within compound $\mathbf{3}$. Treatment of the

(21) Naud, C.; Calas, P.; Commeyras, A. Langmuir 2001, 17, 4851-4857. 
Table 1. Contact Angle Measurements of Glass Slides and Capillaries at Various Stages of Functionalization

\begin{tabular}{|c|c|c|c|c|c|}
\hline \multirow[b]{2}{*}{ surface functionality } & \multirow[b]{2}{*}{ corresponding capillary } & \multicolumn{4}{|c|}{ contact angle (deg) } \\
\hline & & fluid column & static & advancing & receding \\
\hline untreated & capillary A & 55 & $23 \pm 3$ & $25 \pm 3$ & \\
\hline APS (surface 1) & capillary B & 80 & $58 \pm 3$ & $60 \pm 3$ & $25 \pm 3$ \\
\hline furan (surface 2) & capillary C & 78 & $70 \pm 3$ & $72 \pm 3$ & $50 \pm 3$ \\
\hline fluorinated (surface 3) & capillary D & 105 & $101 \pm 9$ & $104 \pm 9$ & $33 \pm 12$ \\
\hline cleaved (surface 2) & capillary E & 81 & $70 \pm 6$ & $70 \pm 6$ & $51 \pm 3$ \\
\hline
\end{tabular}

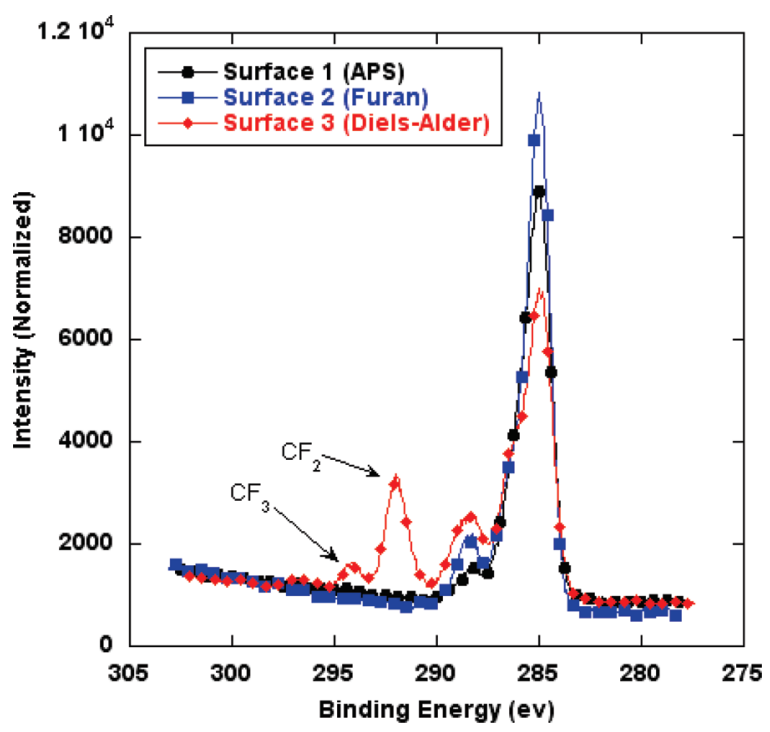

Figure 2. XPS analysis of functionalized surfaces corresponding to those listed in Table 1.

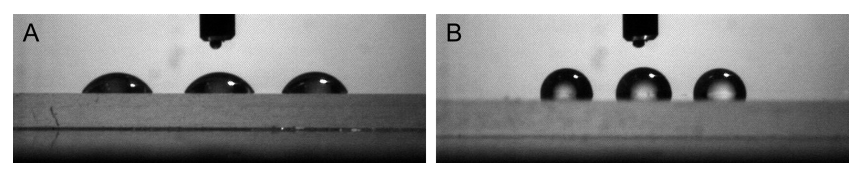

Figure 3. Optical micrograph of contact angle measurements of (A) furan functionalized slide (surface 2) and (B) fluorinated functionalized slide (surface 3).

slides within refluxing toluene induced the retro Diels-Alder reaction and removed the hydrophobic chain end, as indicated by the decrease in contact angle to approximately the same value as that obtained for original furan terminated state $\left(\mathrm{CA} \sim 70 \pm 6^{\circ}\right)$. Figure 3 displays an optical micrograph of surfaces 2 and 3, demonstrating a significant change in the wetability of the surface.

Several attempts were made to explore the versatility of the system to optimize the change in surface energy between the hydrophilic and hydrophobic states. Ideally, the contact angle difference between the hydrophilic and hydrophobic states should be maximized to provide the most efficient driving of fluid from a capillary. Several different diene and dieneophile combinations were explored. (Figure 4) However, only the C4 combination displayed an appropriate change in contact angle. Combinations $\mathrm{B} 1, \mathrm{~B} 2, \mathrm{C} 1$, and $\mathrm{C} 3$ did not display a large enough change in the surface energy. For example, surfaces functionalized with compound $\mathrm{B}$ and $\mathrm{C}$ displayed initial contact angles of $66 \pm 6$ and $70 \pm$ $3^{\circ}$, respectively. Upon formation of the DA adduct, the contact angles changed to $63 \pm 4$ and $64 \pm 2^{\circ}$ for the $\mathrm{B} 1$ and $\mathrm{C} 1$ combination. Other synthetic challenges to consider are the electronics of the Diels-Alder reaction. Typically, the dieneophile must be electron deficient while the diene should be electron rich. For example, compound $\mathbf{2}$ was coupled to an amino terminated slide with a carbodiimide coupling agent to yield a maleimide terminated surface with a contact angle of approximately $65 \pm 2^{\circ}$, which is lower than the furan terminated surface. Next, compound 5 was prepared by coupling together $1 \mathrm{H}, 1 \mathrm{H}-$ perfluoro-1-dodecanol and 2-furfuryl chloride in the presence of $\mathrm{Et}_{3} \mathrm{~N}$. Unfortunately, upon introduction of the fluorinated diene, no Diels-Alder reaction occurred as the contact angle remained unchanged at approximately $65 \pm 2^{\circ}$. By coupling the fluorinated alcohol to the furan ring via an ester linkage, electron density was withdrawn from the diene creating an electron poor diene which inhibited the formation of the Diels-Alder linkage.

Selecting the system depicted in Scheme 1 (combination C4, dieneophile coupled to surface), the methodology was transitioned to glass capillaries. Following analogous synthetic protocols, one $\mathrm{mm}$ internal diameter capillaries were prepared and characterized. As conventional contact angle measurements were not possible inside the capillaries, a series of flow experiments were conducted to observe the impact of surface functionality upon capillary fill. Preliminary work evaluated static capillary fill, where a capillary from each stage of functionalization was oriented vertically and partially immersed into a $\mathrm{H}_{2} \mathrm{O}$ reservoir and the height of capillary fill height relative to the reservoir height was recorded. Attempts to visually capture the capillary fill process were difficult due to scattering and low contrast. Therefore, fluorescein, a fluorescent dye, was dissolved in $\mathrm{H}_{2} \mathrm{O}$, and an optical micrograph was captured under UV conditions. (Figure 5) Table 1 shows the apparent contact angle for these glass capillaries, which can be estimated from the wicked fluid column height $h$ according to eq 1 .

$$
h=\frac{4 \gamma \cos \theta}{\rho g D}
$$

where the fluid has density $\rho$ and surface tension $\gamma$, and exhibits a contact angle of $\theta$ relative to the capillary with internal diameter $D$. The results show that the behavior of the capillary closely follows that of the glass microscope slides, indicating that the treatment is equally applicable to external surfaces and internal flow channels.

As observed with the untreated glass slide, the as-received capillary (A) exhibited hydrophilic properties as indicated by the significant capillary action. Capillaries B and C also displayed fluid advance, although capillary $\mathrm{D}$ displayed little to no capillary action. The presence of the hydrophobic perfluorinated alkyl chains upon the surface prevented spontaneous fluid uptake of the capillary. After thermal treatment of capillary D enabled the retro Diels-Alder reaction to occur, the hydrophobic maleimide was removed from the surface to yield capillary E. The retroDiels-Alder surface exhibited water uptake analogous to capillary $\mathrm{C}$ as the capillary fill for these surfaces was identical within experimental error.

After successfully demonstrating the ability to control capillary fill by manipulating the surface functionality, patterned capillary tubes were prepared by immersing half of the capillary tube within refluxing toluene for $12 \mathrm{~h}$ to induce the retro-Diels-Alder reaction and yield a capillary tube that was hydrophilic along 
Potential Dieneophiles in solution<smiles>O=C1C=CC(=O)N1c1c(F)c(F)c(F)c(F)c1F</smiles><smiles>O=C(O)c1ccc(N2C(=O)C=CC2=O)cc1</smiles>

2<smiles>O=C(OCC(F)(F)F)c1ccc(N2C(=O)C=CC2=O)cc1</smiles>

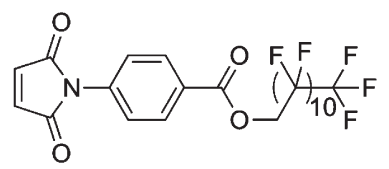

4

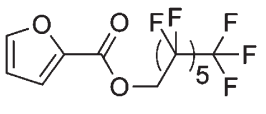

5

Potential Dieneophiles upon the surface

Potential Diene upon the surface

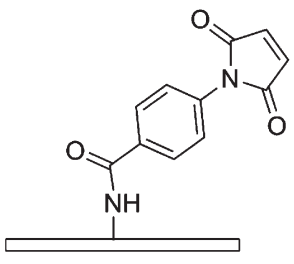

A

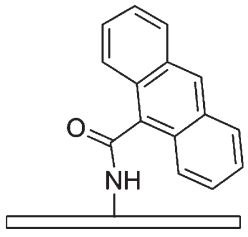

B

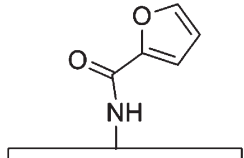

C

Figure 4. Various Diels-Alder systems that were utilized to prepare thermo-responsive surfaces.

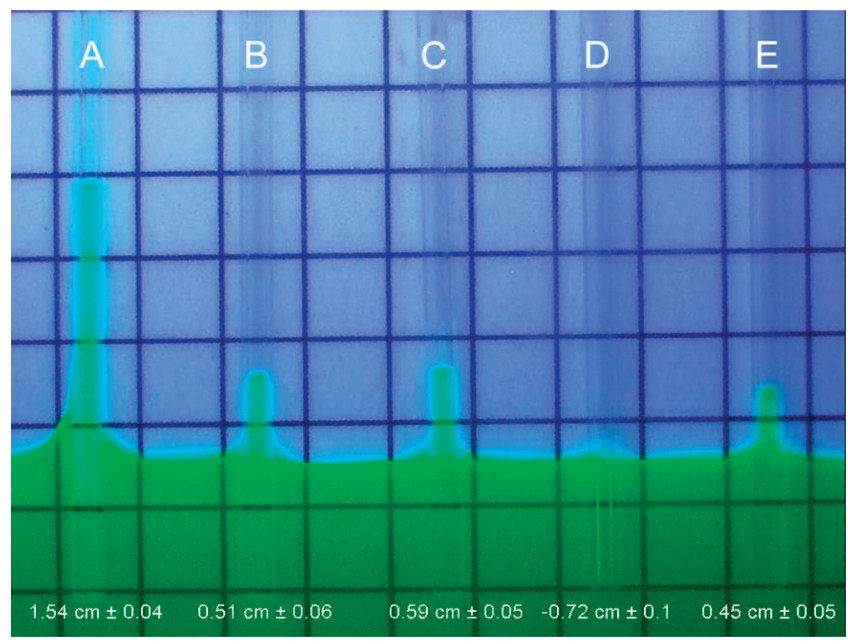

Figure 5. Optical micrograph of capillaries at various stages of functionalization filled with $\mathrm{H}_{2} \mathrm{O}$ containing fluorescein taken under UV conditions. Letters refer to capillaries as denoted in Table 1. Numerical values represent the height of capillary fill. Each grid block represents $0.5 \mathrm{~cm}$. [Note: fluorescent $\mathrm{H}_{2} \mathrm{O}$ was utilized to aid the eye. It has no effect on capillary action.]

half of its length, and hydrophobic along the remainder of its length. To demonstrate the utility of a patterned capillary for flow gating, a fluid slug (dyed water) was introduced into the hydrophilic region of the capillary (Figure 6A). The capillary was then rotated $90^{\circ}$ to a vertical orientation. Upon rotation, the fluid slug falls through the hydrophilic region, as the surface tension forces on either side of the slug exactly balance and the only flow resistance is viscous dissipation due to internal flow. ${ }^{22}$ When fluid slug reaches the hydrophobic zone, however, the advancing slug surface is in contact with a hydrophobic surface, while the trailing slug surface is in contact with a hydrophilic surface (Figure 6B). The resulting contact forces on each surface work in tandem to resist gravity and, if the droplet weight is less than the contact forces (as in this experiment), the droplet is brought to rest. For more massive slugs or slugs driven by other constant external forces (such as electrically driven flows), the slugs can be driven through this transitional zone but the velocity will drop relative to flow through the uniform capillary. Therefore, these types of patterned surfaces can be used to arrest or slow fluid slugs in channel flows.

(22) Kashid, M. N.; Agar, D. W. Chem. Eng. J. 2007, 131, 1-13.
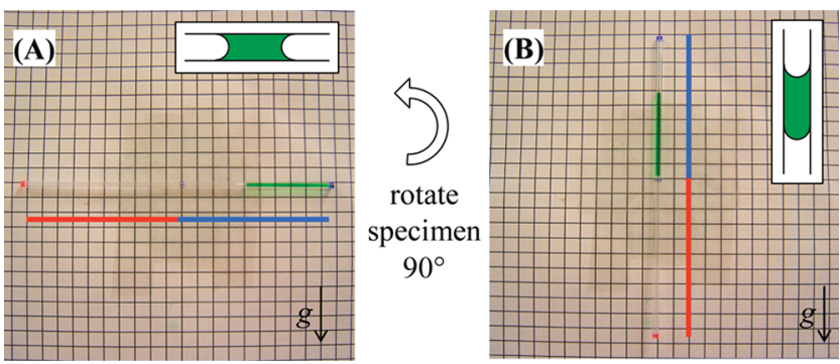

Figure 6. Optical micrograph of a patterned capillary containing an internal fluid slug $\left(\right.$ dyed $\left.\mathrm{H}_{2} \mathrm{O}\right)$. The red line segment indicates the hydrophobic length of the capillary, while the blue line segment indicates the hydrophilic region. Gravity is oriented downward in both images. Inset schematics represent slug interface characteristics for each case.

To further probe the capillary forces within the patterned samples, a dynamic filling experiment was conducted. A schematic of the experimental setup can be observed within the Supporting Information. To briefly describe the experiment, a large fluid reservoir ( $\sim 2 \mathrm{~L})$ was placed upon a vertically adjustable stand to regulate the height of the reservoir. A patterned capillary was then connected to the fluid reservoir via a plastic tube. The bottom of the capillary and the top of the fluid level in the reservoir were set to the same height. The elevation of the reservoir was increased at two mm increments while the capillary maintained a constant position. Between each adjustment of the reservoir, the system was allowed to equilibrate for at least $1 \mathrm{~min}$. Measurements were made from the top of the fluid in the reservoir to the top of the fluid within the capillary. Raising the reservoir was equivalent to lowering the capillary within the fluid reservoir, but this configuration allowed for a precise measurement of fluid level within the tube. The Supporting Information contains optical micrographs of capillaries during the dynamic capillary fill experiment. Figure 7 plots the distance between the top of the reservoir level and the height of fluid within the capillary. Control experiments were conducted with nonpatterned capillaries to observe a baseline, corresponding to the hydrophilic and hydrophobic listing in Figure 7. For the hydrophilic surface, a positive difference between the reservoir and capillary height was observed as the reservoir level was raised. This is in agreement with the static capillary measurements and demonstrates the natural capillary action for a hydrophilic capillary, whereas the hydrophobic surface exhibited a negative difference between the capillary height and reservoir level. Again, this is in agreement with the 
static capillary measurements. The patterned capillary displays three distinct filling regions. Initially, the hydrophilic area of the patterned capillary was attached to the reservoir, which induced capillary action similar to the hydrophilic control experiment. This is denoted by $\mathrm{H}_{1}$, which corresponds to the capillary wetting height for strongly hydrophilic capillary. The capillary action tracked with the control as the height of the reservoir was raised until the fluid level reached the hydrophobic region. At the interface, a second filling region was observed. The advance of fluid in the capillary was hindered by the hydrophobic surface, and a significant height differential was necessary to overcome the interface, corresponding to the Transition filling region. Once the reservoir reached a specific height, the pressure gradient was able to overcome surface tension forces, and the final filling region was reached. Capillary action then proceeded in a manner consistent with the hydrophobic control experiment, corresponding to $\mathrm{H}_{2}$, the capillary wetting height for a weakly hydrophobic capillary. Oscillation within the hydrophobic region is caused by the

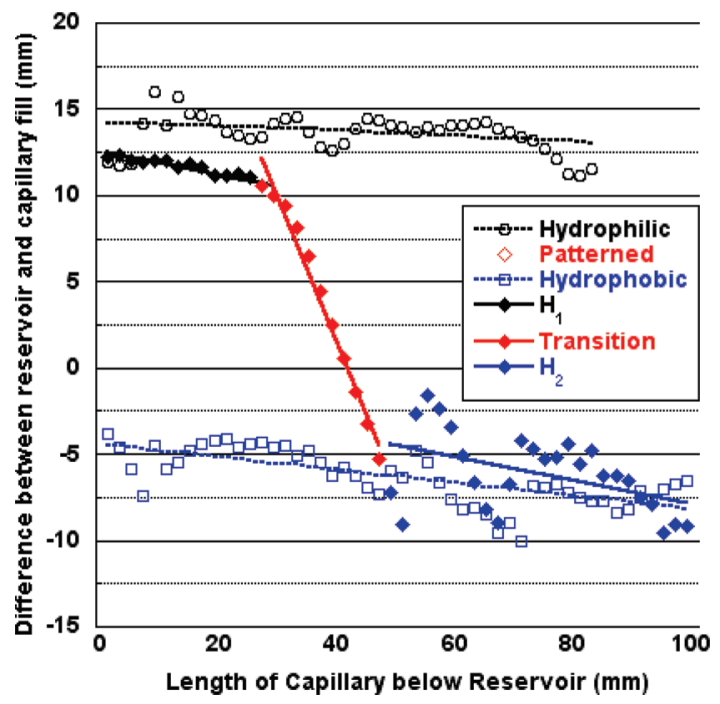

Figure 7. Dynamic capillary fill experiments comparing capillary action in reference to the height of the reservoir against the depth of the capillary. opposition of the surface tension within the capillary and back pressure created by height of the reservoir. This behavior was observed in both the hydrophobic capillaries and the hydrophobic regions of the patterned capillaries. Please see the Supporting Information for further discussion of the dynamic capillary fill experiment.

After clearly demonstrating the ability to pattern capillary surfaces and control capillary action, efforts were made to achieve spontaneous purging of fluid from hydrophobic capillaries to enable the development of self-pressurizing tubules. For a fluidfilled capillary with one surface tension-driven interface and one stress-free interface (Figure 8), the characteristic purge time $\alpha$ is express in eq 2.

$$
\alpha=\frac{4 \mu D}{\gamma \cos \theta} \lambda^{2}
$$

where $\mu$ is fluid viscosity and $\lambda=L / D$ is capillary aspect ratio. (See Supporting Information for complete derivation) The characteristic purge time can be used as a relative metric to compare the effects of fluid, surface, and geometric conditions on the absolute time scale for completely purging a capillary of its vascular fluid. Figure 8 shows characteristic purge time as a function of contact angle and capillary diameter, for a water-filled capillary with an aspect ratio of 100 . Purge times are, in all cases shown, less than $10 \mathrm{~s}$ and, in most cases, less than $1 \mathrm{~s}$. This result shows that capillary-driven purging can be extremely rapid, down to $\mathrm{ms}$ for fine capillaries with strong nonwetting characteristics. Decreasing capillary diameter and increasing contact angle leads to more rapid purging. Note that increasing contact angle from $95^{\circ}$ to perfectly nonwetting $\left(180^{\circ}\right)$ results in a reduction in purge times or only 1 order-of-magnitude. This result indicates that even slightly nonwetting flow channels should provide efficient purging.

Experiments were conducted to demonstrate this self-purging behavior, utilizing fluorinated capillaries (surface 3) and dyed water. The Supporting Information contains schematics of experiments attempted. Unfortunately, self-purging was not observed experimentally. The limiting factor is the hysteretic nature of the functionalized surface. (Table 1) The fluorinated surfaces exhibit hydrophobic character during advancing flow (contact

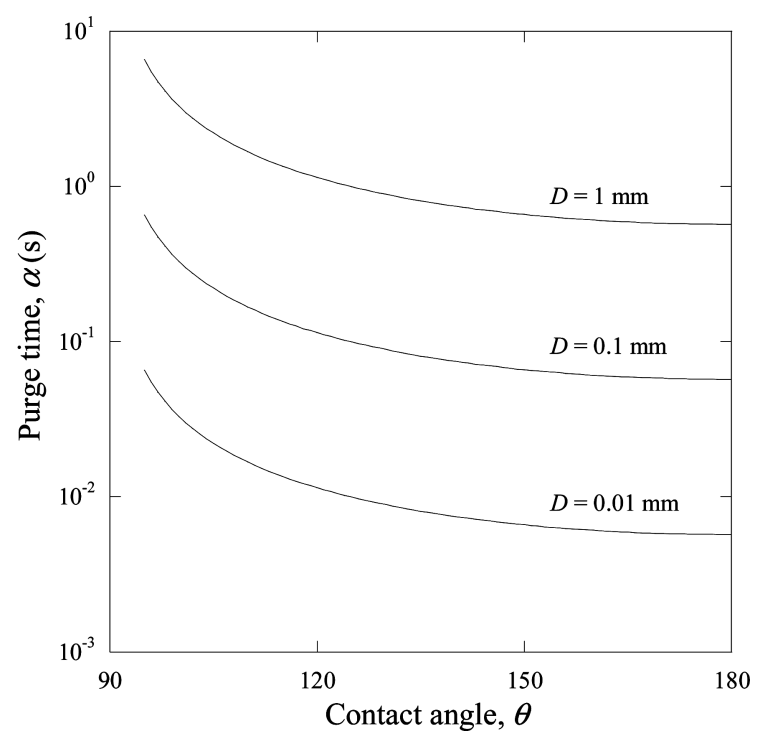

Figure 8. Left: Schematic of purge model. Right: Resulting purge time as a function of contact angle and diameter, for a water-filled capillary with an aspect ratio of 100 . 
angle of $104^{\circ}$ ), but regress to a highly wetting surface during receding flow (contact angle of $33^{\circ}$ ). Therefore, once fluid is introduced into the capillary, the surface energy is altered and there is no longer a driving force to purge the fluid. It is well established that functionalizing glass slides with silanizing agents creates a porous and nonuniform coating. ${ }^{23,24}$ Such a treatment yields a surface with many functional groups; however, not all may be accessible due to steric hindrance. It is therefore hypothesized that residual amine functional groups are still present due to incomplete functionalized. These functional groups are able to $\mathrm{H}$-bond to $\mathrm{H}_{2} \mathrm{O}$ and create a residual hydrophilic surface upon exposure to $\mathrm{H}_{2} \mathrm{O}$. It may also be possible that surface rearrangements are occurring in which the amide, ester and ether bonds present are also able to $\mathrm{H}$-bond to $\mathrm{H}_{2} \mathrm{O}$. Research is currently underway to develop new coating methodology to eliminate this possibility.

\section{Conclusion}

Utilizing Diels-Alder chemistry, thermo-responsive surfaces were prepared. The hydrophilicity of the surface was dictated by the functionalization of the surface. Hydrophobic dieneophiles were prepared and attached to glass slides and capillaries to yield a nonwetting surface. Thermal treatment of the surfaces cleaved the Diels-Alder linkage, and resulted in the fabrication of a hydrophilic surface. Preliminary analysis utilized contact angle (CA) measurements to monitor the change in surface energy, and observed a hydrophilic state $\left(\mathrm{CA}-70 \pm 3^{\circ}\right)$ before attachment of the dieneophile to a hydrophobic state $\left(\mathrm{CA}-101 \pm 9^{\circ}\right)$ followed by regeneration of the hydrophilic state $\left(\mathrm{CA}-70 \pm 6^{\circ}\right)$ upon cleavage of the Diels-Alder linkage. The technology was then transferred to glass capillaries to control capillary fill, which was found to be dependent upon the surface functionality. Patterned capillaries were prepared and effective in serving as gates to inhibit fluid flow. Attempts to demonstrate a self-purging capillary were unsuccessful due to incomplete surface functionalization or surface rearrangement. Residual functional groups such as amines, amides, esters, and/or ethers were most likely involved in $\mathrm{H}$-bonding which resulted in a residual $\mathrm{H}_{2} \mathrm{O}$ layer that would not support a purging phenomenon.

\section{Experimental Section}

Materials. All materials were purchased from commercially available sources and used without further purification. Compound $\mathbf{2}$ was prepared according to previously published methods. $^{25}$

Instrumentation. ${ }^{1} \mathrm{H}$ and ${ }^{13} \mathrm{C} \mathrm{NMR}$ was conducted on either a 300 or $600 \mathrm{MHz}$ Bruker spectrometer in d-Acetone or $\mathrm{CDCl}_{3}$, chemical shifts are reported as $\delta$ (ppm), referenced to the residual solvent peak. Contact angles were measured using a goniometer equipped with a digital camera. XPS analysis was completed at the Materials Research Laboratory at the University of California, Santa Barbara. High resolution carbon scans were collected at a $0^{\circ}$ detector angle. The images were recorded and processed with LabView software. Nanopure water was applied in approximately $2 \mu \mathrm{L}$ droplets. The circle about the droplet was defined and the tangent angle with the surface determined. Capillary surface energy was characterized by immersing the end of a treated capillary into $1.5 \mathrm{~cm}$ of dyed water. The distance of water uptake was measured and recorded.

(23) Jensen, R. E.; Palmese, G. R.; McKnight, S. H. Int. J. Adhes. Adhes. 2006, $26,103-115$

(24) Lee, I.; Wool, R. P. Macromolecules 2000, 33, 2680-2687.

(25) Park, J. O.; Jang, S. H. J. Polym. Sci. A 1992, 30, 723-729.
Synthesis of $\mathrm{N}-(1 \mathrm{H}, 1 \mathrm{H}$-Perfluoro-1-dodecyl phenyl carboxylate) Maleimide (4). A $250 \mathrm{~mL}$ round-bottom flask equipped with a magnetic stirbar was loaded with compound 2 (5.00 g, $23.02 \mathrm{mmol})$ and tetrahydrofuran (THF) $(100 \mathrm{~mL})$. The mixture was stirred until dissolved to which diisopropylcarbodiimide (DIC) $(3.92 \mathrm{~mL}, 25.3 \mathrm{mmol})$ was added and the solution stirred for $15 \mathrm{~min}$. Next, $1 \mathrm{H}, 1 \mathrm{H}$-perfluoro-1-dodecanol (15.00 g, $25.00 \mathrm{mmol}$ ) and dimethylaminopyridine (DMAP) (146 mg, $1.20 \mathrm{mmol}$ ) were added to the solution and allowed to stir overnight at $55^{\circ} \mathrm{C}$. The solution was poured over methanol and the precipitate collected via vacuum filtration to yield compound $\mathbf{4}$ ( $>90 \%$ yield) as a dark red solid. ${ }^{1} \mathrm{H}$ NMR: $\delta(\mathrm{ppm}) 7.61(2 \mathrm{H}, \mathrm{d})$, 7.42 (2H, d), 6.73 (2H, s), $4.82(2 \mathrm{H}, \mathrm{s})$.

Typical Methodology for Surface Preparation. An ethanol$\mathrm{H}_{2} \mathrm{O}(90: 10)$ solution was acidified to $\mathrm{pH} \sim 5$ with glacial acetic acid. Next, (3-aminopropyl) trimethoxysilane $(1 \% \mathrm{w} / \mathrm{w})$ was added and the mixture was allowed to stir for $5 \mathrm{~min}$. The solution was transferred to an appropriate container to which either glass slides or capillaries were added and allowed to incubate for $90 \mathrm{~s}$. Surfaces were then removed from the solution, rinsed with methanol, blown dry with nitrogen and set in an oven at $\sim 50{ }^{\circ} \mathrm{C}$ for $1 \mathrm{~h}$ to yield amine-terminated surfaces.

Next, an appropriate container was loaded with the surfaces (e.g capillaries or glass slides), THF and triethylamine $\left(\mathrm{Et}_{3} \mathrm{~N}\right.$, $0.030 \mathrm{M})$. Next, 2-furoyl chloride $(0.025 \mathrm{M})$ was added, and the surfaces were treated with the reaction mixture at room temperature overnight for $24 \mathrm{~h}$. Then, surfaces were rinsed with ethanol, blown dry with nitrogen and set in an oven at $\sim 50{ }^{\circ} \mathrm{C}$ for $1 \mathrm{~h}$ to yield furan-terminated surfaces.

Finally, an appropriate container was loaded with compound $4(0.03 \mathrm{M})$ and THF and agitated until homogeneous. Next, surfaces were added to the solution and treated for $24 \mathrm{~h}$ at room temperature. After incubation, the surfaces were rinsed with ethanol, blown dry with nitrogen and set in an oven at $\sim 50{ }^{\circ} \mathrm{C}$ for $1 \mathrm{~h}$ to yield DA-terminated surfaces.

Cleavage of the DA was completed by placing the surfaces in refluxing toluene for $24 \mathrm{~h}$, at which point the surfaces were rinsed with ethanol, blown dry with nitrogen and set in an oven at $\sim 50{ }^{\circ} \mathrm{C}$ for $1 \mathrm{~h}$ to reisolate the furan-terminated surfaces.

Capillary Experiments. A typical static capillary fill experiment was conducted by partially immersing a capillary within a fluid reservoir to a depth of $1 \mathrm{~cm}$. To improve visual clarity, glass plates were placed adjacent to the capillary array between the array and the camera. The system was permitted to equilibrate for at least $10 \mathrm{~min}$ prior to recording fluid column heights. For fluid slug experiments, a fluid slug of approximately $30 \mathrm{~mm}$ was drawn into the hydrophilic end of a partially treated capillary via suction. The capillary was oriented horizontally and photographed, and then rotated $90^{\circ}$ to a vertical position and allowed to equilibrate prior to photographing. A typical dynamic capillary fill experiment was conducted by attaching rubber tubing from a large fluid reservoir $(\sim 2 \mathrm{~L})$ to the end of the capillary. The height of the capillary was maintained at a fixed position, while the height of the reservoir was varied in $2 \mathrm{~mm}$ increments. The system was allowed to equilibrate for at least 2 min between height adjustments. The difference between the reservoir height and capillary fluid fill was recorded. Please see the Supporting Information for more synthetic details.

Acknowledgment. Funding and support were provided by the U.S. Army Research Laboratory through the Army Materials Center of Excellence (W911NF-O6-2-0013) program at Drexel University. Additional funding was provided by California Polytechnic State University via start-up funds. Prof. Giuseppe Palmese of Drexel University is acknowledged for stimulating our interest in reversible surface treatments for control of vascular flows. Finally, we would like to acknowledge and thank the Materials Research Facilities Network (MRFN) program at the University of California, Santa Barbara, (NSF-DMR-0520415) 
for providing instrumentation support used to obtain XPS analysis of samples.

Supporting Information Available: Text giving experimental details for capillary fill experiments and the theoretical modeling and figures showing schematics of the experiments, a plot of the ideal theoretical filling experiment, optical micrographs of the experiments, and the problem definition. This material is available free of charge via the Internet at http://pubs. acs.org. 